\title{
Latent Profile Analysis of Manitoban Teachers' Burnout during the COVID-19 Pandemic
}

Dr. Laura Sokal, Jeff Babb, and Dr. Lesley Eblie Trudel

THE UNIVERSITY OF WINNIPEG

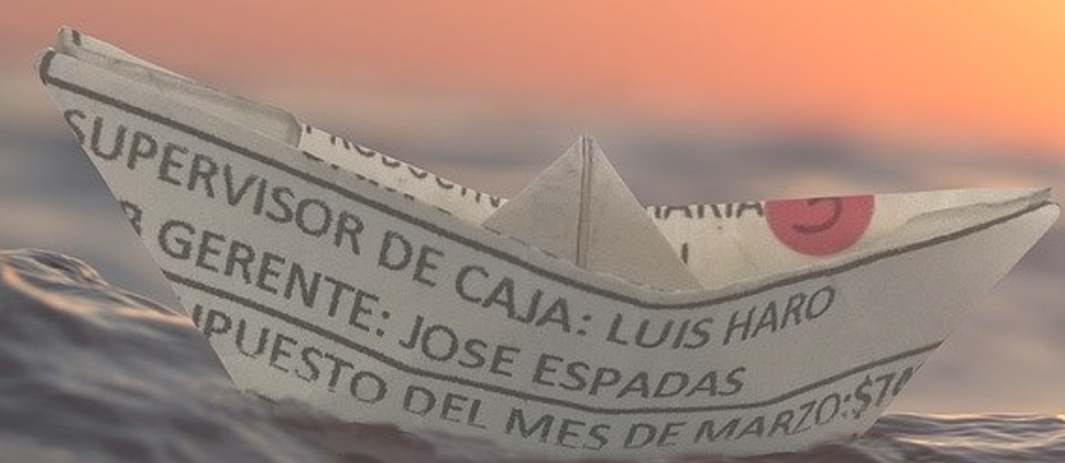

"We are not all in the same boat. We are in different boats in the same storm." 


\section{Acknowledgements}

We would like to acknowledge the generous support of the Social Sciences and Humanities Research Council of Canada in the form of an Explore Grant to Dr. Laura Sokal. We gratefully acknowledge the support of teachers and teacher organizations across Canada who made this survey and interview research possible. Ethics Certificate \# 14993

We would also like to acknowledge the members of our research team on our ongoing project, funded by the Social Sciences and Humanities Research Council of Canada in the form of a Partnership Engage Grant \# 1008-2020-0015, Ethics Certificate \# 14993 to Dr. Laura Sokal, Dr. Lesley Eblie Trudel, and Jeff Babb, and our partners. Our partners are EdCan Network (Andre Rebeiz, Holly Bennett, Sarah Ranby), Canadian Mental Health Association (Marion Cooper, Ela Partyka), Seven Oaks School Division (Supt. Brian O'Leary and Asst. Supt. Matt Henderson). Our stellar Senior Research Assistant is Alina Wilson (graduate of the University of Winnipeg and current teacher), and our superb University of Winnipeg Student Research Assistants are Bailey Riffel, Navneil Singh, and Micah Doerksen (all future teachers).

We gratefully acknowledge the administrators, school trustees, and most of all, the many teachers who have provided their perspectives so that we could amplify their voices to support teachers during the COVID-19 pandemic.

This report was prepared at the request of the Manitoba government. The contents of this report are the intellectual property of the authors. While the authors have agreed to the free distribution of this report in its entirety without permission, no excerpt may be taken from it. These data are part of a national study that is pending publication. 


\section{Table of Contents}

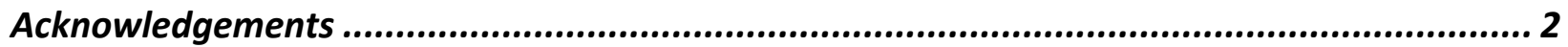

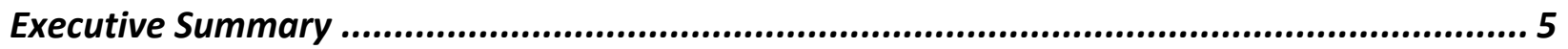

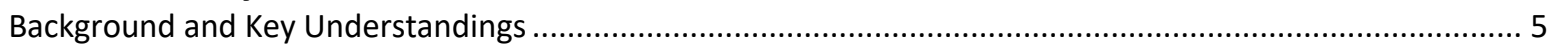

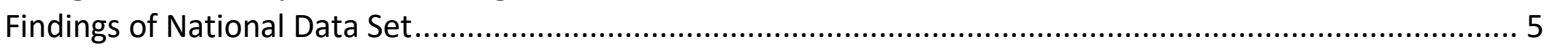

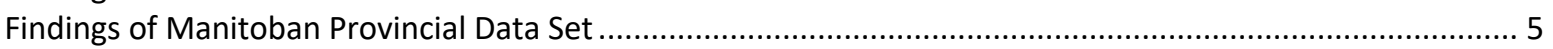

Latent Profile Analysis of Manitoban Teachers' Burnout during the COVID-19 Pandemic ...... 7

Understanding Teachers' Stress during a Pandemic .................................................................... 7

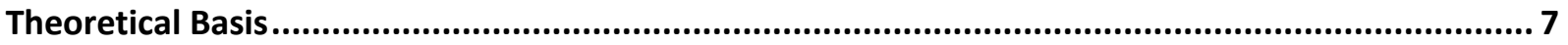

Salient Resources and Demands in the Teacher Burnout Process ................................................... 10

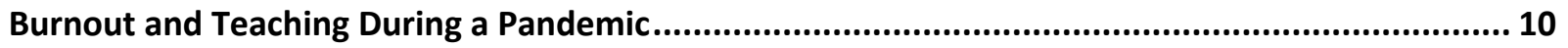

Three Expected Findings in Our COVID-19 and Teacher Burnout Research Program ...................... 11

Three Unexpected Findings in Our COVID-19 and Teacher Burnout Research Program................... 12

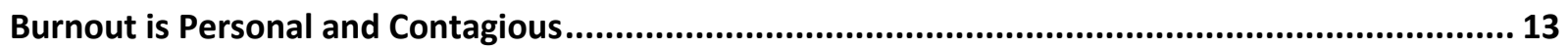

The Appropriate Response is a Varied Response .......................................................................... 14

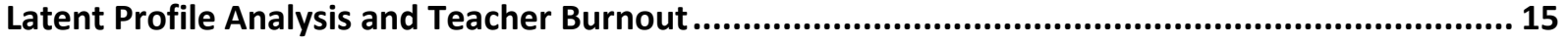

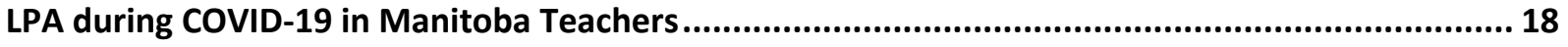

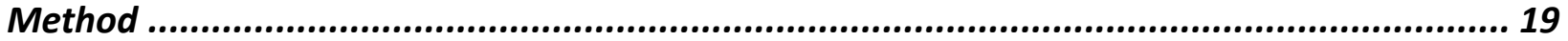

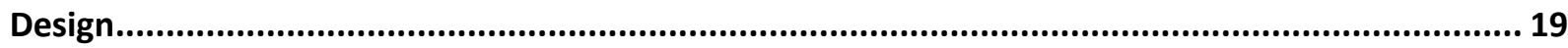

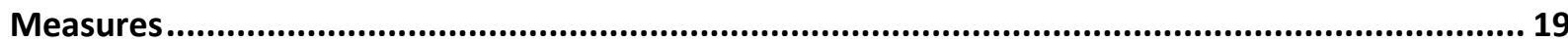

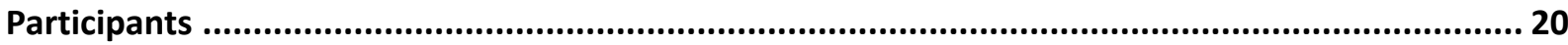

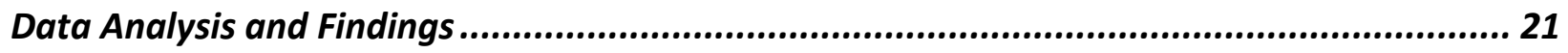

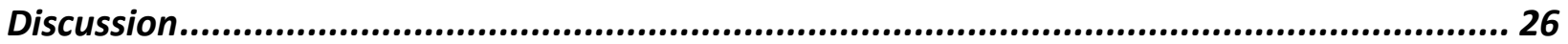

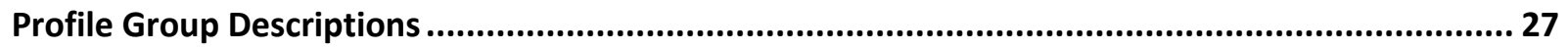

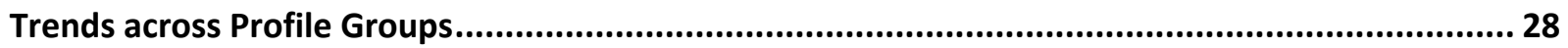

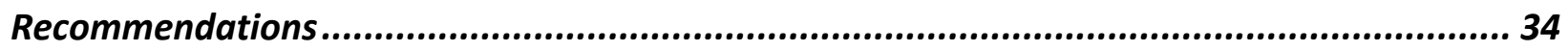

Supports for Teachers with Lower Accomplishment ................................................................. 35

Importance of Administrators for Teachers with Low/Moderate Accomplishment......................... 38

Supports for Teachers with Moderate Accomplishment ................................................................ 39

Supports for Teachers with Higher Accomplishment ...................................................................... 39

The Importance of Multi-level Attention to Burnout ........................................................................... 40

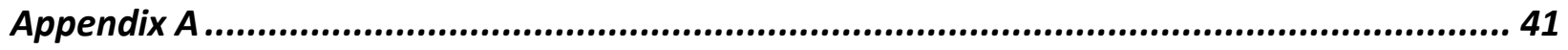

Additional Publications and Media About our Research Program.............................................. 41

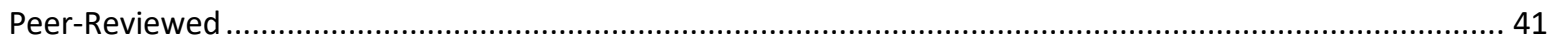

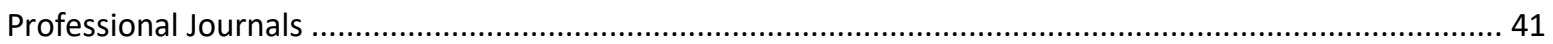




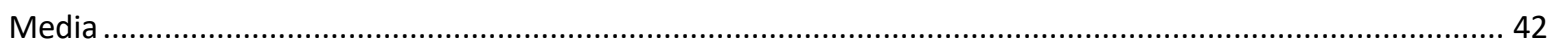

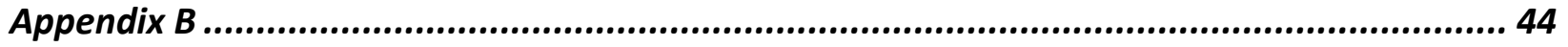

Resources from CMHA prepared as a specific response to these research findings........................ 44

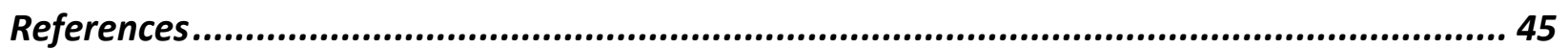




\section{Executive Summary}

\section{Background and Key Understandings}

1. Stress and possible burnout are responses to inadequate access to internal and external resources to meet job demands (p. 7).

2. Burnout in teachers is measured based on three dimensions: (a) Exhaustion (emotional and physical); (b) depersonalization (cynicism and withdrawal of energy from students); (c) loss of accomplishment (feelings that one can no longer teach effectively).

3. Both these theoretical models have been accepted for decades based on copious research support, but neither has been tested under pandemic conditions.

\section{Findings of National Data Set}

1. Teachers in Canada during the COVID-19 pandemic are in some ways behaving as predicted by pre-pandemic models of job demands, resources, and burnout (p. 11).

2. Teachers in Canada during the COVID-19 pandemic differ from the predicted responses to stress in three significant ways (p. 12).

\section{Findings of Manitoban Provincial Data Set}

1. Traditional statistical analysis methods that report common trends for the entire data set were inadequate for our research study, as they failed to capture the diversity of the voices revealed both in the qualitative and quantitative data.

2. We used a relatively new data analysis technique called Latent Profile Analysis on survey data from 1019 Manitoban teachers collected during the first wave of the pandemic (April, June, September 2020), and it showed that teachers are exhibiting five unique profiles of responses (pp. 21-28). These data were verified in our ongoing, bi-weekly follow-up interviews and our focus groups with Manitoban teachers.

3. Each profile can be linked with specific job demands and resources. Comparison of the significant demands and resources in the more highly adapted groups suggests approaches that may be successful with the less adapted groups (pp. 25,27-28).

4. Teachers in the five Manitoban profile groups compared with the five Canadian profile groups (pp. 29-31) demonstrate higher levels of exhaustion in all but one profile group, as well as higher levels of depersonalization in the Detached and Inefficacious groups. Although the accomplishment of Manitoban teachers is higher in all but one profile group than for their counterparts across Canada, there is a larger percentage of teachers falling into the two most concerning groups in the Manitoban sample (45.9\%) than in the Canadian sample (27.2\%). 
5. The small group of teachers who intend to leave the profession can have a significant negative effect on the majority of teachers who are also feeling stress but are coping well (pp. 13-14).

6. Teachers with lower accomplishment would benefit from more social supports, and effective recovery strategies. The Canadian Mental Health Association (CMHA) can assist in this regard with programs, information, and apps (pp. 38, 39, 44).

7. Teachers with higher accomplishment would benefit from job crafting and other strategies of 'voice and choice' to maintain the momentum of their resilience (p. 39).

8. Social connections and supports are important to teacher resilience.

9. School and divisional administration are key players in supporting teacher resilience. CMHA offers courses and resources that can support capacity development to ensure administrators have the skills necessary to engage in leadership of this nature (p. 38).

10. A multi-level response is required to support the development of personal resources and practices for well-being, in addition to external resource provision and demand adjustment, a perspective supported by Canadian Mental Health Association and the World Health Organization. All stakeholders must contribute to the recovery of our school system (pp. 34, 40, 44).

11. We have shared our findings widely (see Appendix A), including an infographics series supported by our research partners at EdCan Network, as well as peer-reviewed papers, and are currently creating a podcast for teachers (produced by Kent Davies of the Oral History Centre at the University of Winnipeg) that discusses the five profiles of teachers' burnout and resiliency found in the national data set. 


\section{Latent Profile Analysis of Manitoban Teachers' Burnout during the COVID-19 Pandemic}

\section{Understanding Teachers' Stress during a Pandemic}

An abundance of international research has demonstrated that teaching is recognized as a rewarding yet highly stressful profession (Herman et al., 2018; Johnson et al., 2005; Skaalvik \& Skaalvik, 2015). While there is no consistent definition of teacher stress, the concept has been portrayed in two distinct ways in the research literature. Otto (1986) identified work-related stress as a mismatch of internal/external resources with the demands of the role, while Kyriacou (2001) and Rudow (1999) described experiences of teacher stress as related to unpleasant and negative emotions involving tension and discontent derived from some aspect of the work. Nonetheless, when teachers experience elevated stress over extended periods of time, the results can include lower quality instruction, negative well-being, ill-health, and possibly burnout and attrition (Alarcon, 2011; Clunies-Ross et al., 2008; Harmsen et al., 2018). Research (Herman et al., 2018; Jennings \& Greenberg, 2009) has clarified, however, that stress management as well as attention to ecological factors within the teaching role can lead to improved social-emotional competence for teachers who are then more likely to remain in classrooms despite inherent challenges. Ott, Hiebert, Rodger and Leschiel (2017) defined such ability to cope and grow through adversity as resilience.

Answering the call of Holmes et al. (2020), we endeavoured to focus on the psychological and organizational aspects of teaching during the challenging time of the COVID- 19 pandemic, including an exploration of the relationship between role demands and resources, stress, and potential burnout for teachers. We selected two well-validated theoretical models that were previously used to examine these variables, with an interest in applying the frameworks under pandemic conditions. With this in mind, we ventured to understand more fully the dynamics of the experiences of teachers, on whom we depend as front-line workers in our educational system.

\section{Theoretical Basis}

Job Resources and Demands. The job demands-resources (JD-R) model (Bakker \& Demerouti, 2007; Demerouti et al., 2001) is the transactional framework that we used to examine the occupational stress of teachers during the pandemic. The model was originally introduced to identify precursors of workrelated burnout due to excessive job demands and insufficient resources. Job demands are defined in the model to include "physical, psychological, social, or organizational aspects of the job that require sustained physical and/or

"This break was medicine-- absolutely
medicine. It totally recharged me. I think it is
partially due to the commitment I made to
myself, which was do not work over the
break. I thought nope, I need a full-on break
from work, and it really helped." 
psychological (cognitive and emotional) effort or skills" (Baker \& Demerouti, 2007, p. 312). Job resources are described as "physical, psychological, social, or organizational aspects of the job that are either functional in achieving work goals, reducing job demands and the associated physiological and psychological costs, or [in] stimulating personal growth, learning, and development" (p. 312). Note here that resources are understood within this model as both compensatory responses to deficits in meeting demands but also recognized as catalysts for growth and development. Further to the work of Otto (1986), stress in relation to the JD-R model has been defined as a subjective appraised mismatch between job demands and resources (Bakker \& Demerouti, 2007; McCarthy et al., 2015). A balance of job demands and resources would signify that individuals - in this case teachers-- could successfully fulfill their role responsibilities (see Figure 1). In contrast, a relative shortage of resources as compared to demands would result in stress, which might eventually lead to burnout and attrition (Harmsen et al., 2018; Maulana et al., 2015). See Figure 2.

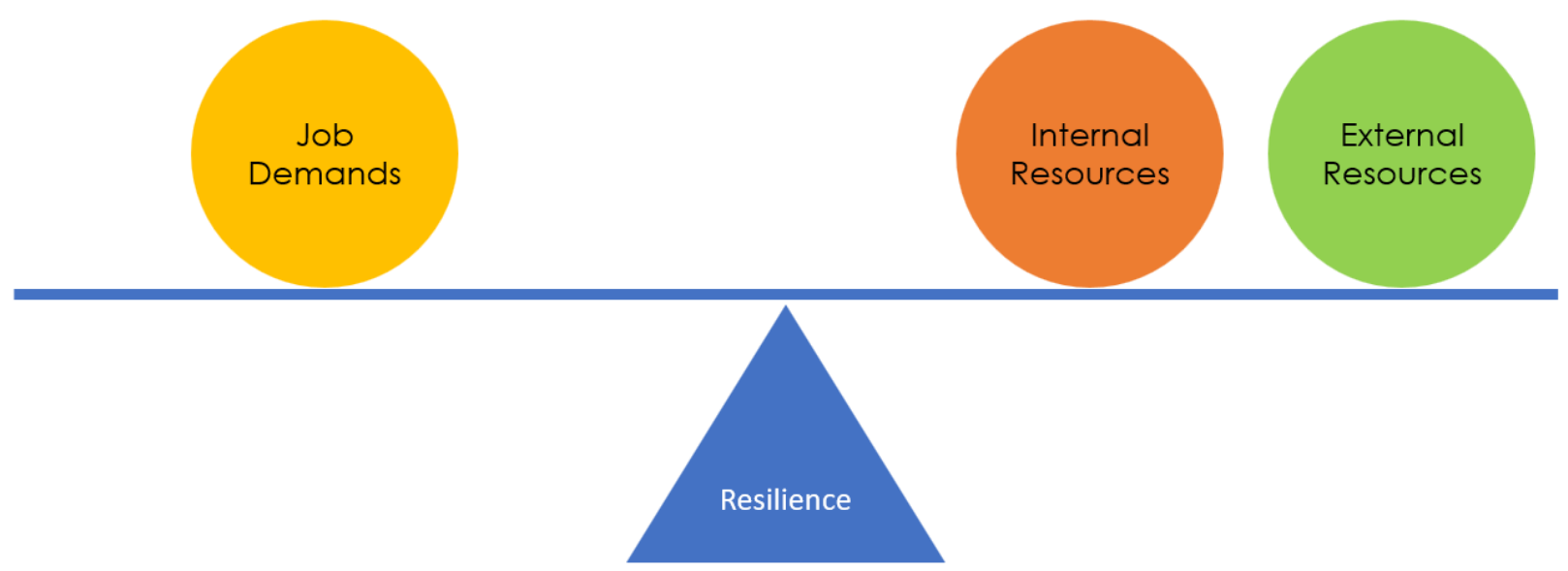

Figure 1: The Job Resources-Demands Model demonstrating Balance and Resilience

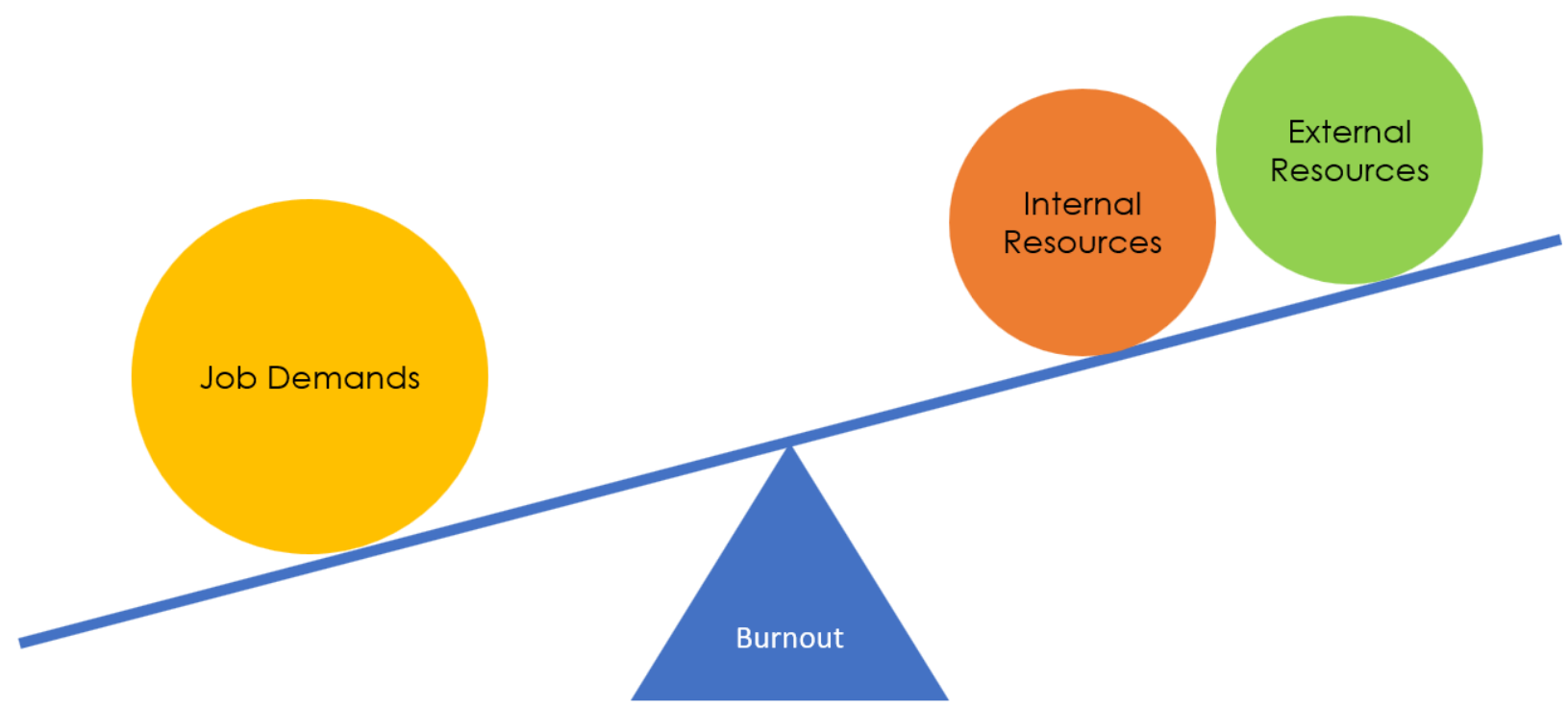

Figure 2: The Job Resources-Demands Model demonstrating Mismatch and Burnout 
Recent revisions to the JD-R model (Bakker \& Demerouti, 2007) have focused on internal resources (Bakker \& Demerouti, 2007; Taris et al., 2017), seen in Figures 1 and 2 , in addition to contextual resources when considering job demands. This addition not only recognized the importance of individual agency in terms of which resources teachers themselves contribute to the balance, but it also recognized the individuality of their judgements about resources they deemed most effective in relation to specific demands (Taris et al., 2017). Past research has shown that internal resources- such as efficacy and positive attitudes toward change-- are associated with higher resiliency and lower burnout (Bouckenooghe, 2009; Tsouloupas et al., 2010).

The enhanced JD-R model (Bakker \& Demerouti, 2007) provides a salient means through which to examine the shifting dynamics of instructional practice during the COVID-19 pandemic, in that it recognizes the changing nature of job demands. The revised 2007 JD-R model is therefore a useful lens for examining the changing job demands, and the internal and contextual resources that together predict teacher resilience or burnout.

The Burnout Continuum. The most accepted model of burnout is offered by Maslach and Jackson (1981). In this model, burnout includes three dimensions: (1) increased emotional exhaustion; (2) increased cynicism or depersonalization, and (3) reduced personal accomplishment (Maslach \& Jackson, 1981; Maslach et al., 1996).

- The first dimension of burnout is exhaustion and is characterized by unrelenting physical, emotional, and mental fatigue. During this phase individuals commit high levels of energy and time to completing their job roles, but cannot keep up with the demands.

- The second dimension of burnout is depersonalization, during which individuals begin to distance themselves from their students and/or work. Individuals at this stage of burnout sometimes feel that they have worked hard to complete tasks but that others are presenting roadblocks. Apathy for others is characteristic of this stage. In other professions that involve lower levels of relational work, this dimension is called cynicism and refers to the withdrawal from the work, rather than from the students. Recent developments suggest that both depersonalization and cynicism can affect teacher burnout (Schaufeli \& Taris, 2005), and these terms are often used interchangeably in publications.

- The final dimension of burnout is loss of accomplishment. In this phase, teachers no longer believe they are capable of fostering student learning and often leave the profession, feeling inadequate and defeated. 
Progression along the burnout continuum is often perceived to occur due to sustained periods of occupational stress. In responding to teacher stress related to demands and resources, Alarcon (2011) found that job demands most strongly correlated with emotional exhaustion, followed by cynicism, and then reduced levels of accomplishment. Inversely, Alarcon (2011) illustrated that resources most strongly correlated with teacher accomplishment, followed by cynicism, and then exhaustion. Collectively, these findings suggest that ameliorating teacher burnout along the continuum requires differential responses dependent on an individual's stage of burnout. According to this theory, whereas individuals with high exhaustion would respond best to decreased job demands, individuals with high cynicism or low accomplishment would respond best to increased resources. By employing the JD-R model alongside the model proposed by Maslach \& Jackson (1981), one is able to determine how teachers perceive role demands and various contextual and personal resources within a specific context-in this case the COVID-19 pandemic.

\section{Salient Resources and Demands in the Teacher Burnout Process}

In addition to the personal resources previously discussed such as attitudes toward change and teacher efficacy (Sokal, Eblie Trudel, \& Babb, 2020b), a key influence cited in many research studies is the power of school leaders to mitigate teacher burnout and attrition (Eyal \& Roth, 2011; Podalsky et al., 2016; Richardson et al., 2008; Urick, 2016). Effective leaders offset the job demands of teachers with available resources and, in turn, can alleviate burnout

"They're trying to prevent rumours, but by not sharing information that is what they are perpetuating --rumours. So, they're not giving us any explanation of the decisions that they are making. I think that breeds more anxiety and more distrust in admin., because then we wonder what else are they not telling US." progression. Leadership actions such as cultivating a caring and empowering work environment through provision of resources (e.g., collaboration time and professional development), as well as emotional and social support, have been linked to positive teacher well-being (Van Maele \& Van Houtte, 2015), sustained organizational commitment (Conley \& You, 2018), and decreased attrition (Hughes et al., 2015; Urick, 2016).

\section{Burnout and Teaching During a Pandemic}

Although the research literature on teacher burnout in general is well established, we still know relatively little about the variation in responses across contexts and individuals (Bianchi, Schonfeld, \& Laurent, 2015). Moreover, the applicability of both models - the burnout continuum and the JD-R model--has not been tested during pandemic conditions. Our research to date has produced over a dozen publications since March 2020 in both peer-reviewed and professional journals (see Appendix A). It not only provides us with some understanding of teacher resilience and burnout within the Canadian context, but also outlines a perspective on the application of the research during the COVID-19 pandemic. 


\section{Three Expected Findings in Our COVID-19 and Teacher Burnout Research Program}

Three of the main findings in our current research program were predicted by prepandemic research about teacher stress and burnout.

First, in terms of personal resources such as efficacy (defined here as subjective perceptions of competence) for using effective strategies, managing behaviours, and engaging students (Tschannen-Moran \& Hoy, 2001), our current research during the COVID-19 pandemic (Sokal, Eblie Trudel, \& Babb, 2020a) showed that all three components of teaching efficacy were significantly and negatively correlated with exhaustion and depersonalization and were significantly, positively correlated with accomplishment in Canadian teachers-- as expected based on pre-pandemic research. Likewise, all three components of attitudes toward change (thoughts, feelings, and behaviours) were significantly and negatively correlated with exhaustion and cynicism, and significantly and positively correlated with accomplishment in our initial Canadian sample.

Second, our national longitudinal study reporting on changes in over 1600 Canadian teachers' burnout during remote teaching across two time points from April to June 2020 showed significant increases in burnout scores over that time (Sokal, Eblie Trudel, \& Babb, 2020b).

Third, our April 2020 data collection showed that in the early stages of burnout, the most effective response was a decrease in demands accompanied by the provision of a curated list of resources. In contrast, it showed that teachers in the later stages of burnout-those experiencing increased depersonalization and decreased accomplishment-responded better to being provided with specific types of resources (Sokal, Eblie Trudel, \& Babb, 2020a). See Figure 3.

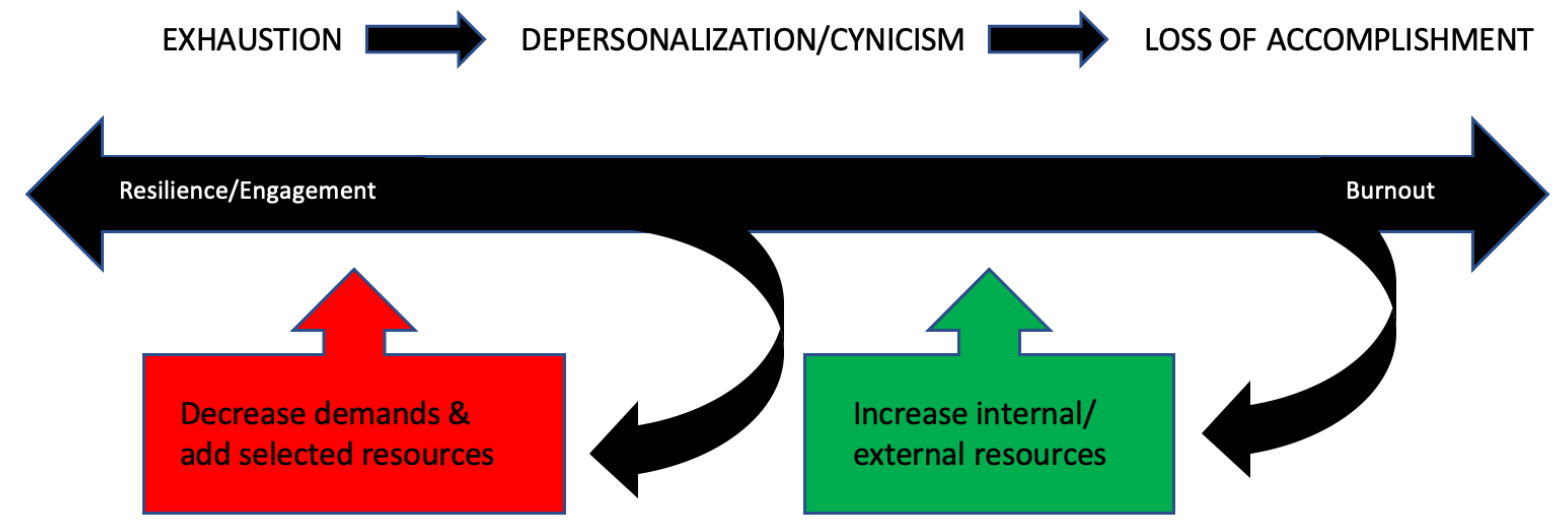

Figure 3: Resources and Demands and Burnout Stages during COVID-19 


\section{Three Unexpected Findings in Our COVID-19 and Teacher Burnout Research Program}

In addition to these expected findings, our explorations of the effects of the COVID-19 pandemic on teacher burnout yielded three unexpected results.

First, in terms of the progression of burnout and attitudes toward change in a national Canadian sample of over 1600 teachers from April 2020 to June 2020 (Sokal, Eblie Trudel, \& Babb, 2020b), we found that teachers did not follow predicted patterns noted in the literature. We expected that teachers would demonstrate increases in all three dimensions of exhaustion, depersonalization, and loss of accomplishment of the burnout scales while concurrently experiencing more negative thoughts, feelings, and behaviours related to change. Instead,

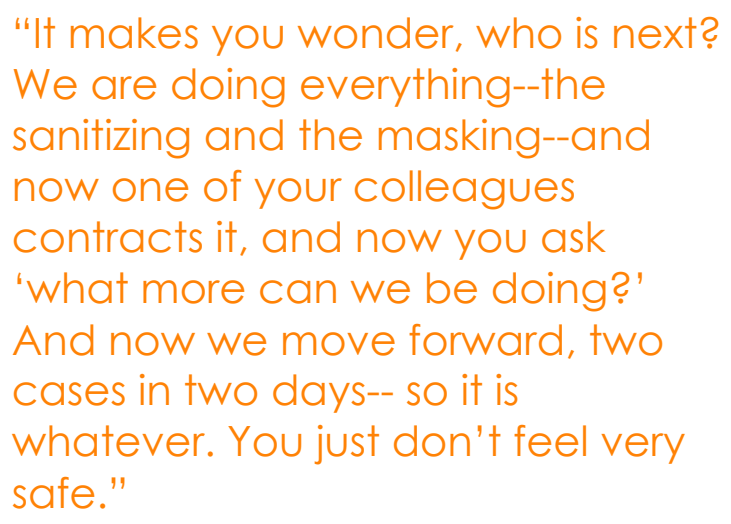

It is possible that the conditions and responses promoted by a global pandemic are not fully captured by the existing, predominant model of burnout. Our research showed that most teachers were rising to the challenge of the pandemic despite elevated personal costs, in that they were maintaining positive behaviours and accomplishment regardless of their increasing exhaustion, depersonalization, and negative thoughts and feelings about the changes brought on by the pandemic.

Second, we observed that Canadian teachers who struggled with the job demands of teaching during a pandemic accused resilient teachers of eliciting "toxic positivity" (Sokal, Eblie Trudel, \& Babb, 2020e), suggesting a division and diversity in teacher coping mechanisms during COVID-19. This observation led us to question whether generalizations could be made about how teachers are experiencing the pandemic. 
Third, the survey that we conducted in Manitoba in September 2020 showed that the role of on-site school leadership was integral to support of the vast majority of Manitoba teachers (92.5\% of those surveyed) during the pandemic, as expected based on pre-pandemic research (Eyal \& Roth, 2011; Podalsky et al., 2016; Richardson et al., 2008; Urick, 2016). This finding echoed our national survey, which also showed the importance of school administrators as resources to teachers (Sokal, Eblie Trudel, \& Babb, 2020a). However, for those who planned to leave the profession $(7.5 \%$ of the Manitoban teachers who were surveyed), the influence of their school leadership was inconsequential. Instead, these teachers cited more global political concerns and a sense of demoralization (Santoro, 2018; Sokal \& Babb, under review) about the state of teaching in general as the reasons for leaving (Sokal, Eblie Trudel, \& Babb, 2020c). Demoralization occurs when

"I think this week alone we have had three people go on stress leave. You just get the emails that say "this person is going on leave, and we wish them all the best" and it's like come on! We all know what is going on, because we know what is going on around the school. There is this 'not talking about it' and 'not naming it' vibe-- which is silly. We have a large staff, and I understand that is challenging, but it really just hollows out any feelings of camaraderie or collegiality when things aren't out in the open. It is demoralizing, I would say." teachers perceive that their change in job context does not allow them to garner the moral rewards of what they view as "good work" (Santoro, 2018). The lack of influence of principals on this small group of teachers runs counter to prior research and suggests that this group is responding in unpredictable ways during the pandemic.

Together, these findings support some aspects of the research found in previous prepandemic studies of teacher burnout, but also run contrary to research regarding other aspects of teacher burnout, and therefore they necessitate further exploration. They not only call into question whether the current models capture teachers' experiences during the pandemic, but they also suggest that not all teachers are responding to the current challenges in the same way.

\section{Burnout is Personal and Contagious}

Theoretical modelling, pre-pandemic research, as well as our data collected in Canada during the current pandemic indicated that individuals at different points of the burnout continuum required different responses. The understanding that burnout is a response to the subjective evaluation of internal and external resources relative to demands highlights the personal and unique ways that teachers as individuals are experiencing the pandemic.

Importantly, our research suggests that the teachers who are resilient-- and who maintain positive perspectives and effective teaching despite increased exhaustion and challenges-- feel silenced by those who are burning out and/or are demoralized (Sokal, Eblie Trudel, \& Babb, 2020e; Santoro, 2018). These conditions do not bode well for educators, as research (Ford, et al., 2019; Maslach, Schaufeli, \& Leiter, 2001) has shown that burnout can have 
a contagious effect by infusing itself into informal interactions between colleagues, resulting in strained interactions, poor school climate, and decreased organizational effectiveness. The findings of these scholars, in addition to our own results, suggest that in order to ameliorate teacher burnout during this pandemic, school and divisional administrators as well as governments must actively address the external demands being placed on teachers as a result of COVID19. In doing so, school systems would not only be responding to the needs of the majority of teachers who remain committed to education, but they would also be responding to the $7.5 \%$ of teachers who are the 'squeaky wheels.'

"It is human nature for people to feed off each other. So, if there is a collective feeling of disgruntlement or dismay, it affects one another. There is still a lot of support going on, but some of the teachers I know who have historically been very chipper or very happy, they are not the same. I have seen some of my best staff break down in tears in front of me, which is heart breaking. Even when we are trying to lift our spirits and raise each other up, daily we are still faced with the realities of what teaching a pandemic is like."

This small minority has the capacity to affect other teachers by diminishing the resilience of their colleagues and inhibiting the outcomes of their students (Klusmann, Richter, \& Lüdtke, 2016).

Considered alongside the warning from Dorcet and her colleagues (2020) regarding the collateral damage that will be caused by ignoring teacher welfare during a pandemic, as well as previous research about teacher burnout, these collective findings buttress calls to support teachers to prevent their burnout and attrition.

\section{The Appropriate Response is a Varied Response}

Given that a range of teacher responses to stress were evident in many of our findings (Sokal, Eblie Trudel, \& Babb, 2020c,2020h), we determined that a different statistical approach to examining teachers' experiences with burnout and stress during a pandemic is required. This is due to the fact that a generalized approach to supporting teacher resilience that presents trends that work for most teachers will fall short in three ways.

- First, it will not recognize that teachers at different points of burnout need different responses (Alarcon, 2011; Sokal, Eblie Trudel, \& Babb, 2020a, 2020g).

- Second, it will diminish individuals' sense that they are being heard, as well as their own agency in their responses to the pandemic and their efforts toward resilience (Sokal, Eblie Trudel, \& Babb, 2020c; Taris et al., 2017).

- Finally, a generalized response that does not address the small group of teachers with the highest levels of demoralization, depersonalization, and burnout will do little to address the negative effects they can have on their colleagues, which in turn will contribute to higher levels of burnout overall (Klusmann, Richter, \& Lüdtke, 2016; Sokal, Eblie Trudel, \& Babb, 2020c). 
Ideally, the new analytic approach would enable us to examine and understand the different patterns of responses in homogeneous sub-groupings within the teaching population, and perhaps assist in the development of differentiated supports which would be more meaningful and authentic for each group of teachers. Given that latent profile analysis provides these affordances, we selected this statistical approach to analyze a subset of our data specific to Manitoba teachers.

\section{Latent Profile Analysis and Teacher Burnout}

Latent profile analysis (LPA) is a relatively new cousin to traditional cluster analysis. LPA, like traditional cluster analysis, is a person-centered approach (Mäkikangas \& Kinnunen, 2016; Pyhältö, Pietarinen, Haverinen, Tikkanen, \& Soini, 2020). Mäkikangas and Kinnunen (2016) conducted a literature review of person-centered approaches to investigating burnout and found that person-centred approaches had only become popular within the previous ten years, generating a total of 24 research studies. Of the 24 studies, only 3 studied teachers (Polish, French, and Swedish), and all three of those studies used traditional cluster analysis. Moreover, only 4 of the 24 studies used LPA, and these 4 were some of the more recent of the studies reviewed. Mäkikangas and Kinnunen (2016) suggested several avenues for further development, including (1) exploring burnout contextually, considering the antecedents as well as individual resources, to generate a more holistic understanding of burnout and (2) moving away from traditional cluster analysis and toward LPA.

LPA is suitable for the current Manitoba-based study in that it meets both of Mäkikangas and Kinnunen's (2016) recommendations and allowed us to explore a variety of contextualized profiles that illustrate different aspects of burnout and responses in teaching (Meyer, Stanley, \& Vandenberg, 2013), particularly in the context of Manitoban teachers during the current pandemic. Furthermore, LPA generates both distinct profiles as well as statistical criteria for model comparisons, allowing opportunities to examine differentiated resources that each group deems effective, and therefore it supports practical application (Meyer, Stanley, \& Vandenberg, 2013). Importantly, Moeller et al. (2018) suggested that this type of modeling allows us to understand patterns of seemingly discordant concurrent characteristics within individuals, such as experiencing high burnout with concurrent high engagement; or, in the case of our own findings (Sokal, Eblie Trudel \& Babb, 2020b) increased exhaustion and depersonalization alongside increased accomplishment.

Since the 2016 review by Mäkikanas and Kinnunen, Finnish and Swedish researchers have taken up the call the use LPA to examine burnout contextually with teachers, although it has not yet been applied to data generated during the COVID-19 global pandemic. A recent study by Pyhältö, et al. (2020) examined pre-pandemic burnout in 2310 Finnish teachers. They identified five distinct profiles that differed in both burnout symptoms and proactive strategy use. The five profiles generated in that study included: (1) No burnout risk (47\% of sample) with low levels of exhaustion, cynicism, and loss of accomplishment, (2) Minor burnout risk (25\%) with moderate levels of exhaustion, cynicism, and loss of accomplishment, (3) Increased exhaustion (19\%) with a 
high level of exhaustion, moderate levels of cynicism and loss of accomplishment, (4) Increased exhaustion and cynicism (6\%) with a high level of exhaustion, moderate levels of cynicism and low loss of accomplishment, and (5) High burnout risk, (4\%) with a high level of exhaustion, moderate levels of cynicism and high loss of accomplishment. In terms of resources, they found that both self- and co-regulation were highest in the first two profile groups who displayed lower burnout, and they were lowest in the last two profile groups who displayed the highest burnout. Furthermore, they found that lower burnout was associated with the development of proactive regulation strategies; however well-developed self-regulation in combination with low coregulation resulted in increased levels of cynicism. These authors concluded that the percentage of teachers falling within the increased or high risk of burnout categories (29\%) is concerning, given the crucial influence of teachers on student well-being (Herman et al., 2018).

Another recent smaller Finnish study was conducted by a Salmela-Aro, Hietajärvi and Lonka (2019). Similar in design to our current study but conducted prior to the 2020 global pandemic, these researchers combined the theoretical work by Maslach, Jackson, \& Schwab (1996) on burnout with the JD-R model of Bakker and Demerouti (2007) to try to determine individual responses and collective profiles of teacher burnout in the context of job demands and resources. In contrast to the five profiles found by Pyhältö et al. (2020), Salmela-Aro et al. (2019) found only two profiles: Engaged (30\%) and engaged-burnout (70\%). The latter group could be described by Santoro (2018) as 'demoralized' - they want to do good work, but are prevented from doing so by systemic and contextual barriers. While both groups were highly engaged in teaching, the latter group demonstrated higher levels of burnout. In terms of job resources and demands, the former group had access to greater job resources and personal resources, whereas the latter group experienced greater work demands. Salmela-Aro et al. (2019) found the latent profile characterized by concurrent high levels of engagement and burnout was a previously unidentified profile of burnout, and they labelled this a "worrying result" (p. 5). Salmela-Aro and colleagues (2019) cited previous studies showing short-term gains but longterm costs of belonging to this group, including higher risk of depression. Higher workload and larger classes were characteristic of the engaged-burnout group, whereas having control was associated with the engaged group. According to the authors, policy makers who control the demands such as class size and workload should give due consideration to the high incidence of teachers in the engaged-burnout group. Furthermore, Santoro (2018) recommended engaging these teachers as problem-solvers in identifying how systems can change to allow them to meet their moral obligations for "good work."

A related study of 816 novice Swedish teachers generated 7 profile trajectories using traditional cluster analysis (Hultell, Melin, \& Gustavsson, 2013) and was one of three studies included in the previously described literature review on person-centred approaches to burnout conducted by Mäkikangas and Kinnunen (2016). While LPA was not used in this particular study, we include its findings for two reasons. First, it explored changes in teacher burnout at four timepoints over the first three years of teaching. Second, in using a person-centered analysis plan as well as a longitudinal design, it was able to confirm whether previous evidence showing burnout as a stable state was a consequence of the methods and analysis used in previous studies. The seven burnout trajectories identified were; (1) Increase (13\%); (2) Decrease (11\%); (3) Increase followed by decrease (10\%); (4) Decrease followed by increase (9\%); (5) Stable low 
(25\%); (6) Stable high (5\%); and (7) Stable moderate (27\%). These researchers found that burnout trajectories, whether progressing or regressing related to burnout, were not always stable, but more importantly were related to changes in both resources (e.g., self-efficacy) as well as outcomes (intention to leave the profession). This is an important finding for two reasons. First, it demonstrated that profile grouping is not a stable individual trait, and second, progression toward burnout (and therefore profile grouping) can be reversed based on changes in the relationships between resources and demands.

LPA is also now being used-and recommended-- by the some of the authors of the Maslach Burnout Inventory (Leiter \& Maslach, 2016). Their study of two samples of healthcare workers found five burnout profiles including: (1) Burnout (high in all three scales, $8 \%$ of sample 1 and $4 \%$ of sample 2), (2) Engagement (low in all three scales, $44 \%$ of sample 1 and $47 \%$ of sample 2), (3) Overextended (high only in exhaustion, 11\% of the sample 1 and $17 \%$ of sample 2), (4) Disengaged (high only in cynicism, $7 \%$ of the sample 1 and $12 \%$ of sample 2 ), and (5) Ineffective (high only in lack of accomplishment, 31\% of the sample 1 and $20 \%$ of sample 2). It should be noted that while these data were gathered from those in the 'helping professions' (i.e., two large samples of Canadian healthcare workers), they were not gathered from teachers. However, this study provides important insights for the current research interests related to teachers during a pandemic. The authors suggested that interventions must be geared to the needs of those within each profile group in order that they move away from burnout and toward resilience (these authors call resilience "engagement"). Moreover, they proposed that latent profiles are specific to each profession and sample, and that further research should explore other samples of workers in different contexts. As such, an examination of teachers within pandemic conditions may reveal necessary information on the appropriate responses specific to the profiles we reveal. Importantly, Leiter and Maslach (2016) posited that people who fall in the last three profiles they identified in their research--where workers exhibit concerning scores in only one of the three dimensions of burnout-could represent those who are moving toward burnout, but they could also represent those who have experienced burnout and are now recovering due to corrections of the mismatch in the balance of work demands to resources specific to the context.

The final study we will explore used LPA on a sample of teachers. Herman, Hickmon-Rosa, and Reinke (2018) examined a sample of American teachers and used stress, coping, burnout, and efficacy as the variables in their study. They found 4 profiles: (1) high levels of stress and burnout with low levels of coping and efficacy (3\% of sample); (2) high stress with moderate coping and burnout (30\% of sample); High stress and coping and low burnout ( $60 \%$ of sample), and (4) low stress and burnout with high coping and efficacy (7\% of the sample). Importantly, these scholars linked the various profiles to both student behaviour and achievement, which supports the effects of various levels of burnout and profiles of teachers on student outcomes. They suggested that adaptation to the high level of stress experienced by $93 \%$ of the teachers in their sample must be addressed not only with helping teachers to manage their stress (internal resources), but must also address the factors within their ecology that result in their stress and burnout (external demands and resources). Like Leiter and Maslach (2016), they proposed that identifying the needs specific to each profile group is an effective way to mitigate teacher attrition and reverse their progression toward burnout. Although the most burned out teachers 
in Herman et al.'s study, similar to the $7.5 \%$ of Manitoban teachers who plan to leave the profession (Sokal, Eblie Trudel, \& Babb, 2020c), clearly presented the most concerning group, these authors noted that other teacher profile groups have additional commensurate needs that-- if addressed-- could enhance their teaching as well as the outcomes of their students.

Together, these findings suggest that a more nuanced understanding of the profiles of teacher burnout-- within the context of job demands and internal and external resources-would allow us to tailor contexts and minimize or reverse teacher burnout trajectories and attrition.

\section{LPA during COVID-19 in Manitoba Teachers}

Using a sub-set of the national data collected in April, June, and September 2020, we conducted LPA specific to teachers in Manitoba with a view to answer the following questions:

1. Given that differences in the number and nature of profiles across studies suggest that context is important, which burnout profiles are evident in Manitoban teachers during the COVID-19 pandemic?

2. Which job demands and related internal and external resources are associated with each teacher burnout profile?

3. Given the noted job demands and resources for each teacher burnout profile, what types of responses are recommended to support Manitoban teachers' resilience during the COVID-19 pandemic? 


\section{Method}

Design

The study was funded by a grant to Laura Sokal from the Social Sciences and Humanities Research Council of Canada and approved by the University Human Research Ethics Board (certificate number 14993). The methods and measures have been described elsewhere in previous publications based on data at different time points during the study (Sokal, Eblie Trudel, \& Babb, 2020a, 2020b, 2020d, 2020e, 2020f, 2020g, 2020h), and the qualitative interviews (Eblie Trudel, Sokal \& Babb, in press) using only the April survey sample sub-sample. The current study has a quantitative design, based on three surveys including the Manitoba sample conducted in April, June, and September 2020.

Acknowledging the time constraints of the pandemic, teachers from across Canada were recruited by the snowball method, where each participant was requested to pass along the invitation to participate to other eligible contacts. In this case the invitation and online survey link were initially emailed to university professors in faculties of education as well as to teachers' professional organizations across Canada. The request was for Canadian in-service teachers to complete a consent form and survey about their experiences teaching during the initial months of the COVID-19 pandemic. Teachers participated through an online survey housed on Survey Monkey. It took an average of 15 minutes to complete the 92-question, anonymous survey, as many questions used Likert scales.

\section{Measures}

Demographics. We collected data about teachers' gender, age, years of teaching experience and levels of education. Please see Table 1.

Burnout. We used the Maslach Burnout Inventory for Educators (MBI-ES) (Maslach \& Jackson, 1981). This is a 22-item instrument that measures the characteristics of burnout, including exhaustion, depersonalization, and personal accomplishment (Maslach, Jackson, \& Schwab, 1996). It uses a 7-point Likert scale indicating the frequency with which educators agree with the statements: 0 (never); 1 (a few times since beginning teaching at home); 2 (once a month or less); 3 (a few times a month); 4 (once a week); 5 (a few times a week) 6 (every day). Three examples of statements are: "I feel emotionally drained from work" (exhaustion); "I don't really care what happens to some students" (depersonalization); and "I have accomplished many worthwhile things in this job" (accomplishment).

Teaching Efficacy. We used the Teacher Sense of Self-efficacy scale (Tschannen-Moran \& Hoy, 2001) to measure teaching efficacy. This measure includes 12 questions related to three aspects of efficacy (strategies, behaviour, and engagement). Each question was posed on a Likert scale from 1 (not at all) to 9 (a great deal). Sample items include, "In your current work situation, to what extent can you provide an alternative explanation or example when students are confused?" (efficacy with strategies); "In your current work situation, to what extent can you control disruptive behaviour?" (efficacy with behaviour management); and, "In your current 
work situation, to what extent can you help your students value learning?" (efficacy with engagement).

Attitudes toward Technology. To measure attitudes towards technology we used 6 items from a sub-scale developed by Edison and Geissler (2003), supplemented with an additional statement to reflect the current change to technology-based teaching: "I am comfortable with my abilities with the technology I need to use in my current teaching." Participants responded using a 6-point Likert scale ranging from 1 (strongly disagree) to 6 (strongly agree). An example statement is, "I know how to deal with technological malfunctions or problems."

Attitudes Toward Change. Kin and Kareem's (2017) Teacher Attitudes Towards Change Scale (TATC Scale) was used. This scale includes 9 items measuring three main constructs, including cognitive, affective, and behavioural responses to change and uses a 6-point Likert scale. Possible responses were 1 (strongly disagree), 2 (disagree), 3 (moderately disagree), 4 (moderately agree), 5 (agree), and 6 (strongly agree). Example statements are, "I often suggest changes for my school" (cognitive response to change), "Change frustrates me" (affective response to change), "In general, change often helps me perform better" (behavioural response to change).

Job Demands and Resources. Based on the literature, we developed a list of 5 demands and 15 resources, both personal (e.g., self-care such as healthy eating and mindfulness) and external (e.g., support or challenges from parents and administrators). Teachers were asked to indicate the degree to which they perceived each as contributing to their stress or support, respectively. Both resources and demands were measured on a Likert scale ranging from 1 (not at all) to 6 (a great deal).

\section{Participants}

In total, almost 2200 Canadian educators completed the surveys in April, June, and October collectively. People who indicated they were not teachers (e.gs., administrators, clinicians, etc.), those who did not respond to every item of the survey, and those from outside Manitoba were excluded from the analyses. As a result, 1019 Manitoban teachers' data were analysed. See Table 1 for demographic information.

Table 1: Demographic information

\begin{tabular}{|l|c|}
\hline \hline & Number of participants \\
\hline Gender & 160 \\
\hline Male & 845 \\
\hline Female & 1 \\
\hline Other & 11 \\
\hline Don't wish to say & \\
\hline Age & 42 \\
\hline Under 26 & 167 \\
\hline $26-30$ & 353 \\
\hline $31-40$ & 290 \\
\hline $41-50$ & 167 \\
\hline Over 50 & \\
\hline Teaching Experience & 39 \\
\hline Under 1 year & 179 \\
\hline $1-5$ years & 228 \\
\hline $6-10$ years & 213 \\
\hline $11-15$ years & 359 \\
\hline Over 15 years & \\
\hline Education & 867 \\
\hline Less than a Bachelor's degree & 295 \\
\hline Bachelor's degree & 126 \\
\hline Some graduate work & 22 \\
\hline Masters & \\
\hline PhD & \\
\hline
\end{tabular}




\section{Data Analysis and Findings}

A multivariate statistical clustering methodology, known as latent profile analysis (LPA), was used to investigate the three Maslach Burnout Inventory (MBI) subscales of exhaustion, depersonalization and (loss of) accomplishment. Each subscale score for a respondent is a mean of several variables, each variable being the respondent's reaction to a 7-point (range 0-6) Likert scale item from the Maslach burnout questionnaire: exhaustion ( 9 variables); depersonalization (5 variables); and accomplishment (8 variables). LPA enabled us to consider variation in MBI subscale scores of individual anonymous teachers and to determine distinct profiles, ( $a k a$ classes), of burnout risk. The methodology also allowed us to apply statistical criteria to compare statistical models and to guide us in choosing an appropriate number of latent classes.

We implemented the data analytic strategy adopted by Pyhältö, Pietarinen, Haverinen, Tikkanen, and Soini (2020) in their paper on burnout profiles for teachers in Finland. This involved three steps:

Step 1: Extract latent burnout profiles without covariates. That is: focusing solely on burnout measurement data to identify latent profiles (classes).

Step 2: Assign each individual teacher to their most likely class membership.

Step 3: Explore relationships between burnout measures and covariates.

A three-step process for identifying latent profiles and investigating the covariates of latent profile membership was discussed in an earlier paper by (Asparouhov \& Methén, 2014).

Since the publication of the $\mathrm{MBI}$ questionnaire, a level of alpha values has been reported ranging from .81 to .92 for exhaustion, from .57 to .82 for depersonalization/cynicism, and from .50 to .86 for accomplishment (Aguayo, Vargas, de la Fuente \& Lozano, 2011). Given that these wide ranges are dependent on specific samples, Aguayo, Vargas, de la Fuente and Lozano (2011) suggested that Cronbach's alpha values should be calculated and reported based on the specific data sets from which conclusions will be drawn. In keeping with this advice, we generated Table 2. Hulin, Netemeyer, and Cudeck (2001) suggested that alpha of .60 to .70 indicates an acceptable level of reliability.

\begin{tabular}{lcccccccccc} 
& No. of & & & & \multicolumn{4}{c}{ First } & Third \\
MBI subscale & items & Alpha & $\mathrm{n}$ & Mean & SD & Min & quartile & Median & quartile & Max \\
\hline Exhaustion & 9 & 0.81 & 1019 & 4.1386 & 1.2810 & 0.111 & 3.333 & 4.333 & 5.111 & 7.000 \\
Depersonalization & 5 & 0.66 & 1019 & 1.9187 & 1.2802 & 0.000 & 1.000 & 1.800 & 2.800 & 6.400 \\
Accomplishment & 8 & 0.63 & 1019 & 4.0508 & 1.1345 & 0.625 & 3.250 & 4.000 & 4.875 & 7.000 \\
\hline
\end{tabular}

Table 2: Cronbach's alpha values and Descriptive Statistics for the MBI scales, Manitoba data

Table 2 lists descriptive statistics (the Cronbach alpha, mean, standard deviation, minimum, first quartile, median, third quartile, and maximum) on the MBI subscales for data on 
1,019 Manitoban teachers who participated in our national survey on teacher burnout during the Covid-19 pandemic. The table also lists the value of the Cronbach alpha measure of reliability for each subscale. The Cronbach alpha values were computed using the alpha function available as part of the R statistical package psych for personality, psychometric, and psychological research (Revelle, 2020).

We used the R statistical package tidyLPA (Rosenberg, Beymer, Anderson, Van Lissa \& Schmidt, 2018) to conduct LPA and to partition the set of respondents into a number of MBI profiles on the basis of their $\mathrm{MBI}$ subscale scores. We considered four model parameterizations:

Model 1: Equal variances and covariances fixed to zero.

Model 2: Varying variances and covariances fixed to zero.

Model 3: Equal variances and equal covariances.

Model 4: Varying variances and varying covariances. (The tidyLPA package calls this Model 6).

For each model parameterization, we considered the five choices of 2, 3, 4, 5 and 6 latent classes. To compare performance of the 20 combinations of the models and number of classes, we applied an analytic hierarchy process, based on five commonly used information criteria: Akaike's Information Criterion (AIC); Approximate Weight of Evidence (AWE); Bayesian Information Criterion (BIC); Classification Likelihood Criterion (CLC); and Kullback Information Criterion (KIC). The method, developed by Akogul \& Erisoglu (2017), is applied to a $20 \times 5$ decision matrix derived from the AIC, AWE, BIC, CLC and KIC values for the four models, and is available as part of the tidyLPA software package in $\mathrm{R}$.

The decision matrix that we obtained for our application of LPA to the MBI subscale data for Manitoba is shown in Table 3. The analytical hierarchy method of Akogul \& Erisoglu (2017) suggested that it would be best to use the model 2 parameterization (varying variances and covariances fixed to zero) with five latent classes (profiles). In our larger national study of teacher burnout during the Covid-19 pandemic (Babb, Sokal, \& Eblie Trudel, under review), this choice of model 2 with 5 classes was also identified as most appropriate. The Latent Profile Analysis (LPA) of Manitoban teachers revealed five profile groups: Detached $(17.7 \%)$; Inefficacious (28.2\%); Over-extended (27.7\%); Involved (17.2\%); and Engaged (9.2\%). 


\begin{tabular}{ccccccc}
\hline & & \multicolumn{5}{c}{ Information criterion } \\
\cline { 3 - 7 } Model & Classes & AIC & BIC & AWE & CLC & KIC \\
\hline 1 & 2 & 9634.94 & 9684.20 & 9782.05 & 9616.35 & 9647.94 \\
1 & 3 & 9514.63 & 9583.60 & 9721.24 & 9487.95 & 9531.63 \\
1 & 4 & 9492.17 & 9580.85 & 9758.23 & 9457.47 & 9513.17 \\
1 & 5 & 9483.82 & 9592.21 & 9809.31 & 9441.10 & 9508.82 \\
1 & 6 & 9486.00 & 9614.09 & 9871.00 & 9435.18 & 9515.00 \\
& & & & & & \\
2 & 2 & 9527.47 & 9591.51 & 9719.28 & 9502.74 & 9543.47 \\
2 & 3 & 9445.99 & 9544.52 & 9741.66 & 9407.38 & 9468.99 \\
2 & 4 & 9450.12 & 9583.14 & 9849.79 & 9397.49 & 9480.12 \\
2 & 5 & 9395.80 & 9563.31 & 9899.62 & 9328.99 & 9432.80 \\
2 & 6 & 9401.24 & 9603.23 & 10008.96 & 9320.49 & 9445.24 \\
& & & & & & \\
3 & 2 & 9553.06 & 9617.10 & 9744.76 & 9528.44 & 9569.06 \\
3 & 3 & 9477.45 & 9561.20 & 9728.68 & 9444.72 & 9497.45 \\
3 & 4 & 9471.43 & 9574.89 & 9782.15 & 9430.64 & 9495.43 \\
3 & 5 & 9474.57 & 9597.73 & 9844.79 & 9425.67 & 9502.57 \\
3 & 6 & 9471.36 & 9614.23 & 9900.87 & 9414.58 & 9503.36 \\
& & & & & & \\
4 & 2 & 9483.05 & 9576.65 & 9764.23 & 9446.08 & 9505.05 \\
4 & 3 & 9475.37 & 9618.24 & 9905.24 & 9418.24 & 9507.37 \\
4 & 4 & 9383.97 & 9576.11 & 9962.02 & 9307.20 & 9425.97 \\
4 & 5 & 9440.00 & 9681.40 & 10166.68 & 9343.12 & 9492.00 \\
4 & 6 & 9381.09 & 9671.76 & 10256.23 & 9264.29 & 9443.09 \\
\hline & & & & & &
\end{tabular}

Notes:

Model 1: Equal variances and covariances fixed to zero.

Model 2: Varying variances and covariances fixed to zero.

Model 3: Equal variances and equal covariances

Model 4: Varying variances and varying covariances

Model 4 is referred to as Model 6 in the tidyLPA software package.

Profiles and classes are equivalent terms.

Table 3: Model fit indices of LPA for All Models Considered with 2, 3, 4, 5 and 6

Profiles, Manitoba data

After obtaining the five latent profiles, we used tidyLPA to identify the profile group for each respondent. For each $\mathrm{MBI}$ subscale, Table 4 lists the mean, standard deviation and z-score for each of the five latent profiles. The subscale means for each profile are also depicted in Figure 4. 


\begin{tabular}{|c|c|c|c|c|c|c|c|c|c|c|c|c|c|c|c|}
\hline & & $\begin{array}{l}\text { Detached } \\
\text { Profile } 4 \\
\mathrm{n} 4=180\end{array}$ & & & \begin{tabular}{l}
\multicolumn{1}{c}{ In- } \\
efficacious \\
rofile 1 \\
n1 = 288
\end{tabular} & & & 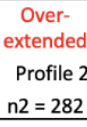 & & & $\begin{array}{l}\text { Involved } \\
\text { Profile } 5 \\
\text { n5 }=175 \\
\end{array}$ & & & $\begin{array}{c}\text { Engaged } \\
\text { Profile } 3 \\
\text { n3 }=94 \\
\end{array}$ & \\
\hline MBI subscale & Mean & SD & $z$ & Mean & SD & $z$ & Mean & SD & $z$ & Mean & SD & $z$ & Mean & SD & $z$ \\
\hline Exhaustion & 5.35 & 0.74 & 0.95 & 4.90 & 0.56 & 0.59 & 3.60 & 1.09 & -0.42 & 3.23 & 1.12 & -0.71 & 3.14 & 1.39 & -0.78 \\
\hline Depersonalization & 3.75 & 0.91 & 1.43 & 2.12 & 0.88 & 0.16 & 1.76 & 0.73 & -0.13 & 0.78 & 0.35 & -0.89 & 0.07 & 0.10 & -1.44 \\
\hline Accomplishment & 3.75 & 1.114 & -0.27 & 3.81 & 1.058 & -0.21 & 4.05 & 1.204 & 0 & 4.44 & 0.97 & 0.345 & 4.73 & 0.867 & 0.602 \\
\hline
\end{tabular}

Table 4: MBI subscale Means and Standard Deviations for Each Profile, Manitoba Data.

After conducting LPA on the MBI subscale data, the relationships with twelve covariates were explored for each profile: five job demands subscales and seven job resources subscales. The demands and resources were taken from the survey data, where we asked the participants to tell us, on a six-point Likert scale, how much each item on a list of five demands contributed to the stress of their job and how much each item on a list of 15 resources supported them in their job. Being as there were 15 resources, we used principal component analysis and cluster analysis to create clusters in order to present like resources together. Given the importance of administrator support in the research literature, we analyzed this variable separately, however the set of the other 14 resource variables partitioned into six groups: (1) Colleagues and Parent/Guardian supports; (2) Friends and Family supports; (3) Professional Learning about strategies (instruction in new methods and technology); (4) Physical health activities (sleep, healthy eating and exercise); (5) Well-being activities (meditation and mindfulness); and (6) Introspective activities (prayer, counselling, and journaling).

For each of the five profiles, Table 5 lists the correlations of the MBI subscales with the job demands subscales and the job resources subscales. When interpreting these profile correlations, we chose to consider only significant correlations at the .05 and .01 level where the coefficient $r$ is .10 or larger in absolute value, given that smaller absolute $r$ values are indicative of negligible effect sizes (Cohen, 1992). Pearson correlation coefficients indicated that each of the five teacher profiles correlated with different job demands and resources. 


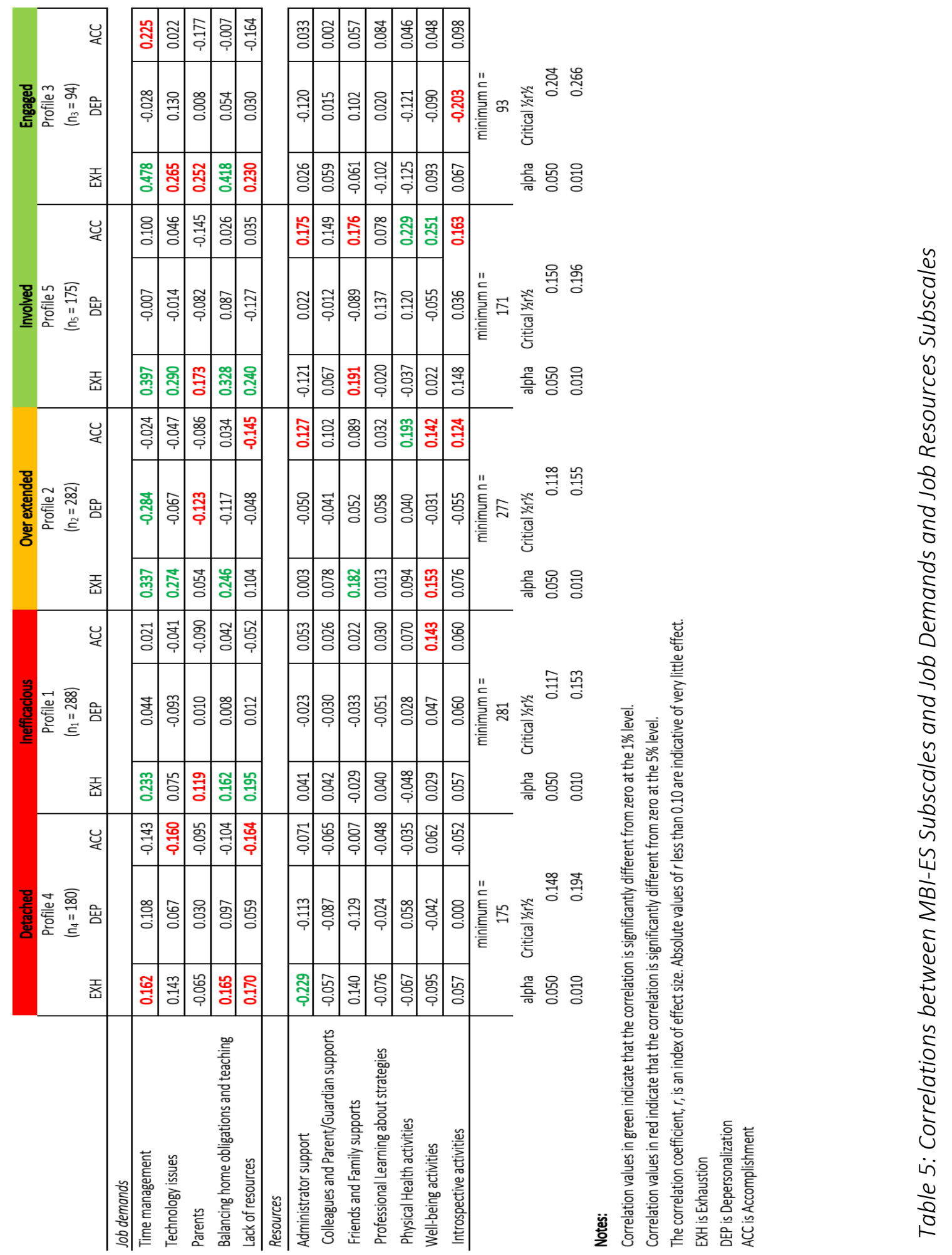




\section{Discussion}

As indicated in Tables 4 and 5, and in Figure 4, the five profile groups presented five distinct patterns of teacher responses to teaching during the pandemic in Manitoba. To find meaningful direction for supporting teachers in each group, an examination of the salient demands and resources specific to each group is essential. These profile groups were further supported by representative, colour-coded, teachers' quotations from our current and ongoing research program involving interviews and focus groups with Manitoba teachers presented in the following profile group descriptions and throughout the report.

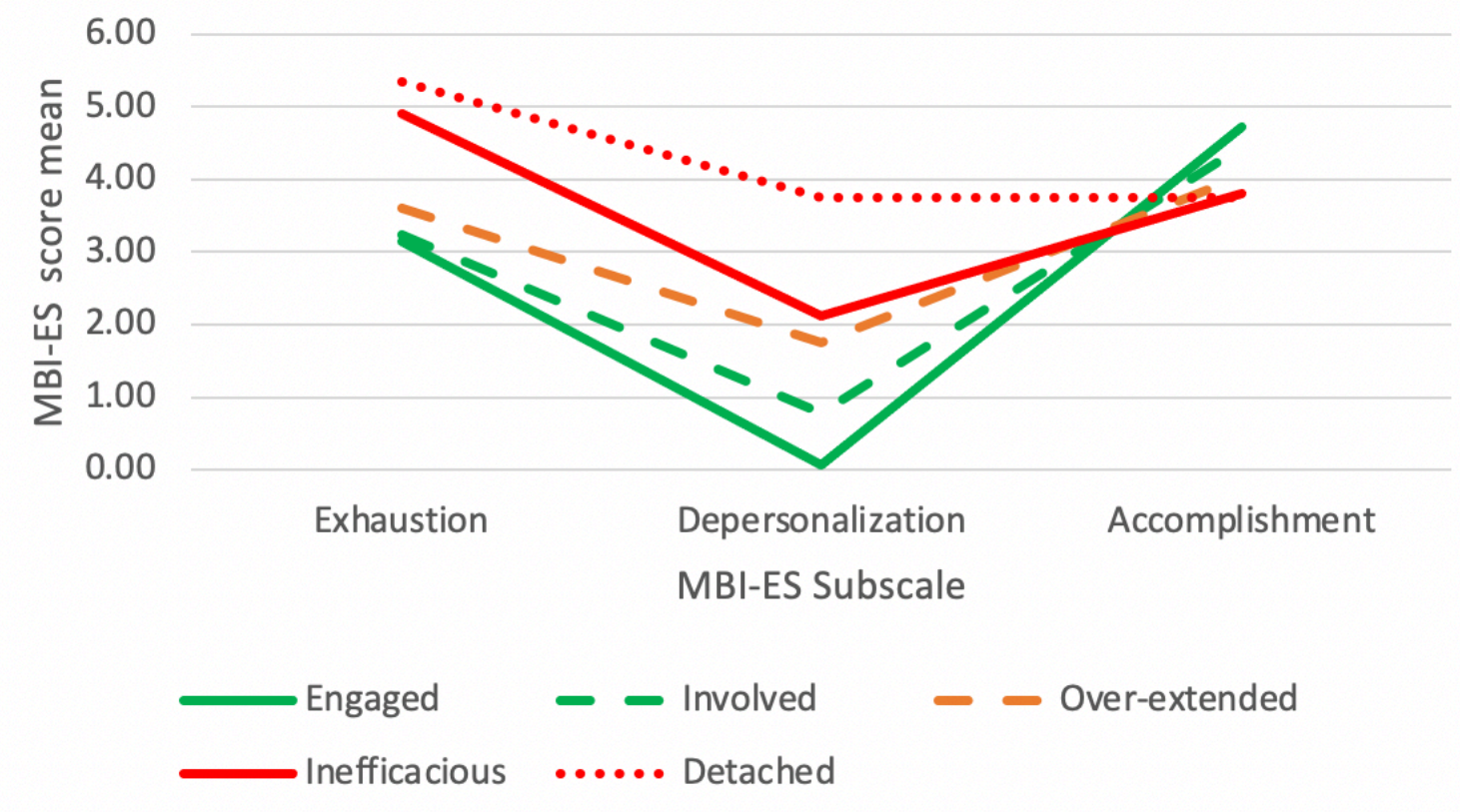

Figure 4: Graph of Manitoba Teachers MBI-ES score means by MBI-ES Subscales 


\section{Profile Group Descriptions}

Detached teachers ( $n=180,17.7 \%$ ) were characterized by the highest exhaustion, highest depersonalization, and the lowest accomplishment within the five profile groups. The three $\mathrm{MBI}$ subscales demonstrated six significant correlations, including five with job demands and one with resources. In terms of demands, time management, and work-life balance, and lack of resources correlated significantly with exhaustion, "For parent/teacher conferences, we were told and challenges with technology and lack of resources correlated with low accomplishment. In terms of supports, this grouping of teachers perceived that support from administrators significantly correlated with decreased exhaustion. No resources correlated significantly with levels of depersonalization or accomplishment. we had to do virtual conferences, and then we had to use a prescribed program that no one was familiar with. I didn't. I don't care, because if parents don't care enough to sign up or read the report card, then I am not chasing you. So, I will probably get in trouble for that down the road. Normally it would matter to me, but this year it doesn't matter to me at all. Because I am doing my part coming here every day to do this job, and I didn't sign up to teach in a pandemic, and so if you can't meet me halfway, then I am not chasing you. Yes, I am just apathetic towards it."

Inefficacious teachers ( $n=288,28.2 \%$ ) were characterized by the second highest exhaustion, second highest depersonalization, and second lowest accomplishment. The three $\mathrm{MBI}$ subscales

"Energy level is about the same. Perspective: I am getting fed up, I guess is the word. I am done with COVID. I am done with the whole pandemic-- I'm just done." demonstrated five significant correlations, including four with job demands and one with resources. In terms of demands, time management, balancing home and work life, parental demands, and lack of resources correlated significantly with exhaustion. In terms of supports, well-being activities were significantly correlated with accomplishment. There were no significant correlations between resources and either exhaustion or depersonalization.

Over-extended teachers ( $n=282,27.7 \%$ ) were characterized by the third highest exhaustion, third highest depersonalization, and third highest accomplishment. The three MBI subscales demonstrated twelve significant correlations, including six with job demands and six with resources. In terms of demands, time management, technology issues, and balancing home and work life all correlated significantly with exhaustion; time management and parental demands correlated "As we shuttle into the actual learning, and getting past the day-to-day cleaning, the kids are really getting into learning and doing projects." negatively with depersonalization; and lack of resources correlated negatively with accomplishment. There were no resources that significantly correlated with depersonalization. However, several supports that were significantly perceived 
to foster accomplishment included administrator support, physical health activities, well-being activities, and introspection activities. In addition, support from friends and family and well-being activities correlated with exhaustion.

Involved teachers ( $n=175,17.2 \%$ ) were characterized by the second lowest exhaustion, second lowest depersonalization, and second highest accomplishment. The three MBI subscales

"I have been having fun with the kids-- the kids are fun. We have been wrapping up different projects, which is nice. It is pretty good--we are trucking along, and everybody is healthy. We haven't had any cases in my classroom, same with my husband's classroom, and my kid's classrooms." demonstrated eleven significant correlations, including five with job demands and six with resources. All five demands (time management, technology issues, balancing home and work life, parents, and lack of resources) correlated with exhaustion. In terms of resources, support from family and friends correlated with increased exhaustion. No supports correlated with depersonalization. Support from

administrators and support from friends and family as well as physical health activities, wellbeing activities, and introspective activities correlated with greater accomplishment.

Engaged teachers ( $n=94,9.2 \%$ ) were characterized by the lowest exhaustion, lowest depersonalization, and highest accomplishment. The three MBI subscales demonstrated seven significant correlations, including six with job demands and one with resources. Bakker \& Demerouti (2014) argued that teachers who perceive both high demands and high resources demonstrated significantly greater engagement in terms of vigour, dedication and flow. In terms of demands, all five job demands (time management, technology issues, students' parents, balancing home and work life, and lack of resources) correlated significantly with exhaustion, while time management was also correlated with accomplishment. In terms of supports, engaged teachers perceived no supports as being correlated with exhaustion, or accomplishment, while depersonalization was negatively correlated "I think there have been good things
that have come from having to
change how we're educating and
really step back to figure out what's
important. I've enjoyed going
through that process, even though
this week in particular-- this virtual
learning-- is very, very challenging,
there's been some positives as well." with introspective activities.

\section{Trends across Profile Groups}

The five unique profiles are interesting in their own right, however comparisons between them yield interesting insights about the range of demands and resources that prove significant to different profile groups as we move from lower levels to higher levels of success in navigating the challenges of teaching in a pandemic: Detached (17.7\%); Inefficacious (28.2\%); Overextended (27.7\%); Involved (17.2\%); and Engaged (9.2\%). 
First, it is clear that the Manitoban data set is demonstrating trends across the sub-scales of burnout. In each case, as the level of exhaustion increases, so does the level of depersonalization. Both these increases are predictive of a loss of accomplishment. The smallest group of Manitoban teachers fall within the Engaged profile and demonstrate the lowest levels of exhaustion and depersonalization, and the highest levels of accomplishment. The group with the most concerning profile is the Detached profile group with the highest exhaustion and depersonalization, and the lowest accomplishment.

Second, compared with teachers across Canada (Babb, Sokal, \& Eblie Trudel, under review), there is some encouraging news but also some concerning news. LPA conducted on the entire Canadian data set also revealed five profile groups. When we compared the mean exhaustion, depersonalization, and accomplishment levels - the three dimensions of burnoutin Manitoban teachers compared to Canadian teachers, interesting trends are revealed.

In terms of exhaustion, the level of exhaustion is higher in Manitoban teachers than in other Canadian teachers in all groups except the Over-extended group. See figure 5.

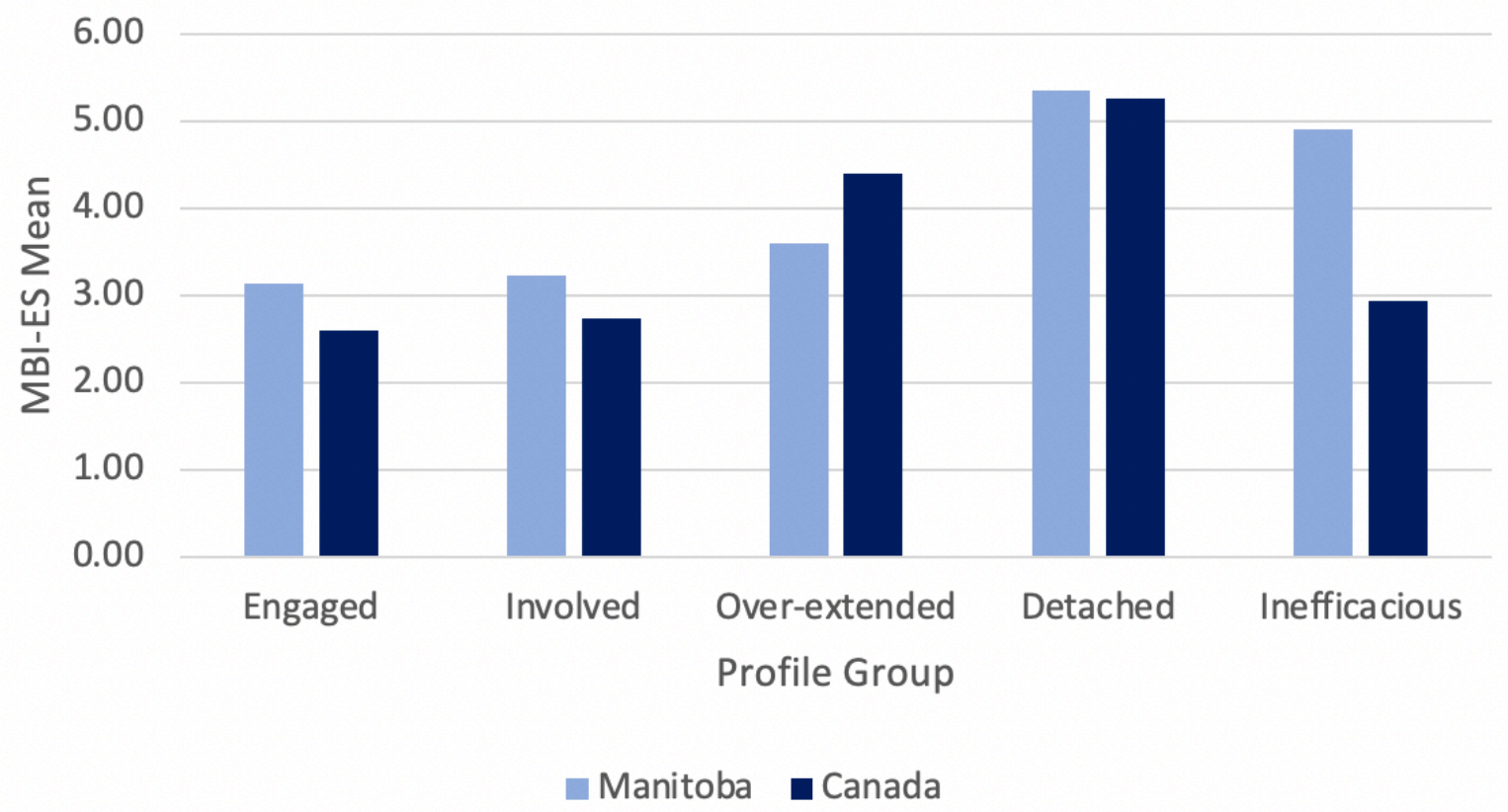

Figure 5: Comparison of Manitoban and Canadian Teachers' Exhaustion by Profile Group

In terms of depersonalization, the flourishing Manitoban groups (Engaged and Involved) are demonstrating lower depersonalization than the national average, but the struggling groups (Detached and Inefficacious) are demonstrating higher depersonalization levels than other Canadian teachers in those groups. See Figure 6. 


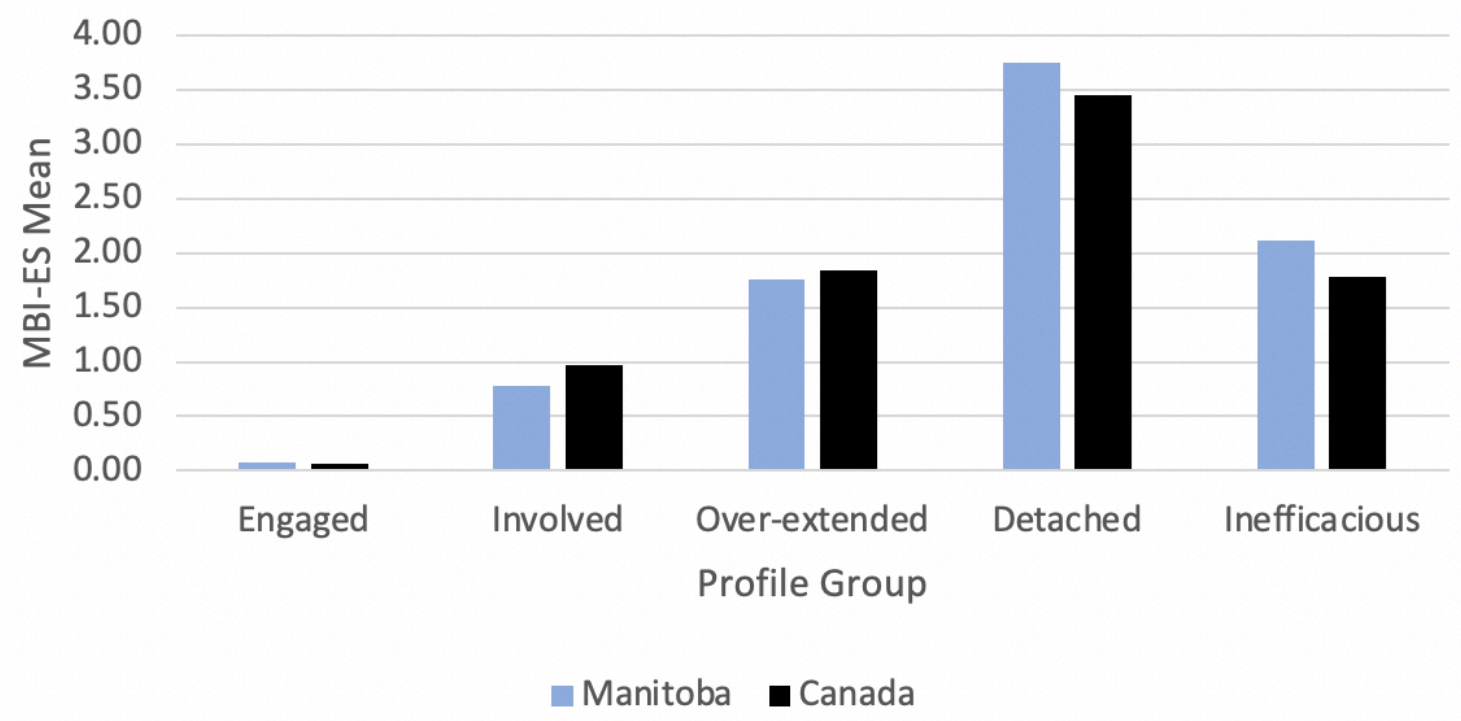

Figure 6: Comparison of Manitoban and Canadian Teachers' Depersonalization by Profile Group

In terms of accomplishment, teachers in Manitoba in all profile groups are demonstrating greater accomplishment than other Canadian teachers within the same profile groups in all groups except in the Involved group, where the means are quite similar. See Figure 7

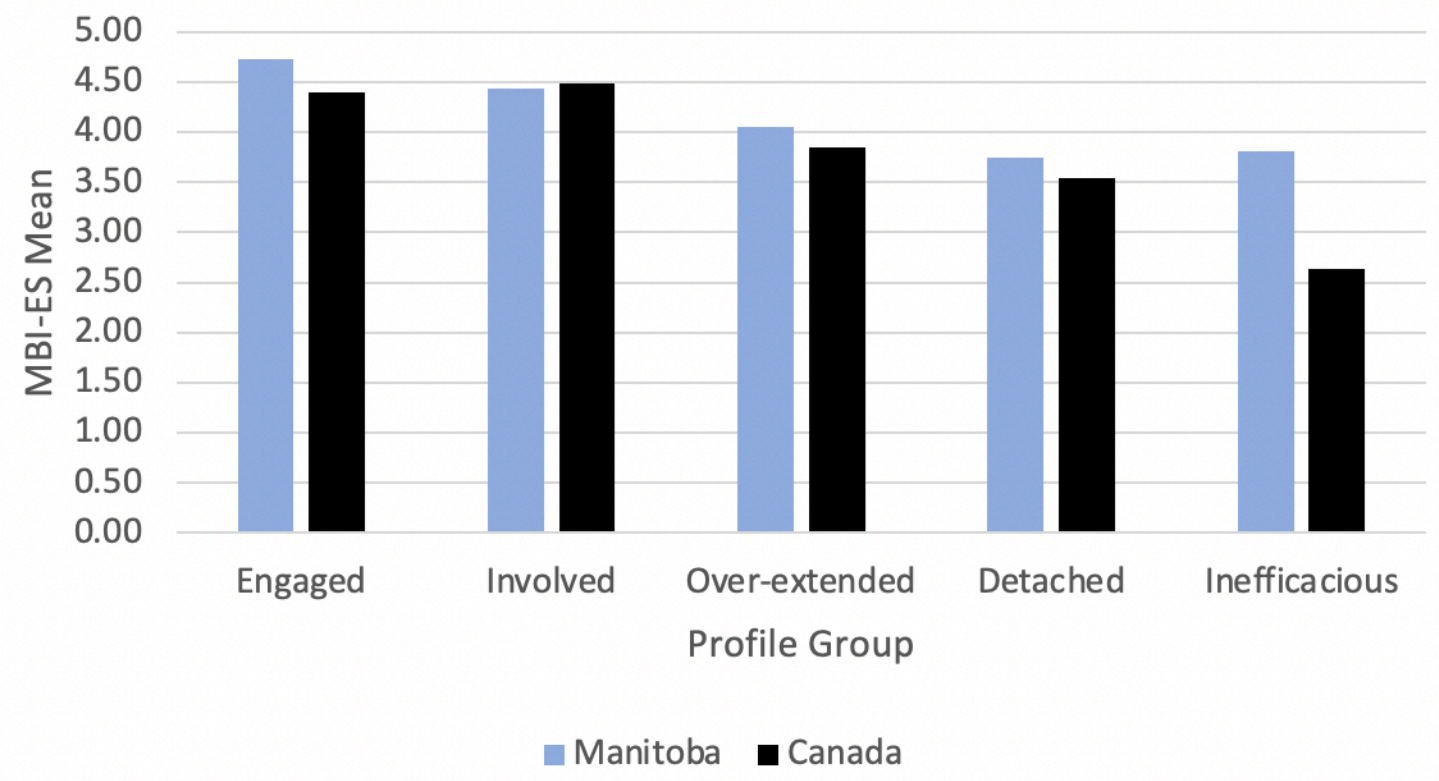

Figure 7: Comparison of Manitoban and Canadian Teachers' Accomplishment by Profile Group

In terms of distribution by profile group comparing Manitoban teachers to other Canadian teachers, we found that there was a greater proportion of Manitoban teachers (45.9\%) in the two struggling groups (Inefficacious and Detached) as compared with other Canadian teachers (27.2\%) in these two profile groups. This trend suggests that for many Manitoban teachers, the focus will be on recovery rather than maintenance of resiliency. Given that research has shown that burnout increases risk in multiple dimensions, both personally and 
professionally, and from teachers to their students (Rupert et al., 2015), substantial attention will be required to mitigate this situation.

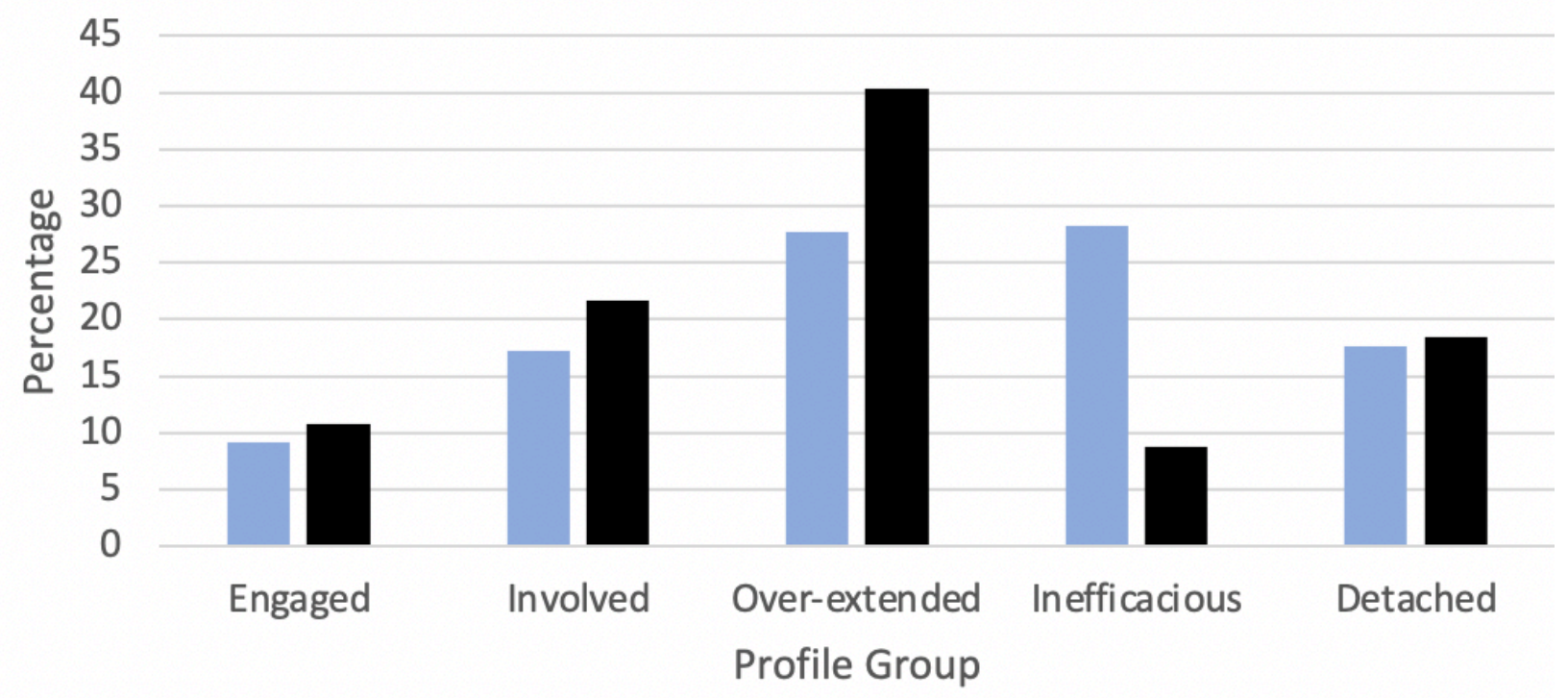

\section{Manitoba Canada}

Figure 8: Distribution of Teaching in Each Profile Group Compared for Manitoba and Canada

Figure 8 suggests that while other Canadian teachers are clustered within the 'tipping' point (in the Over-extended group) between thriving (Engaged and Involved groups) and struggling (Inefficacious and Detached groups), a greater proportion of Manitoban teachers are past that point and are now struggling.

Third, when we consider the trends across the groups progressing from those who are struggling to those who are coping the best, there is a clear trend relating burnout to the relative number of job demands to resources, in all except one case. Considering the relative number of job demands to resources in each group, we see: Detached (5/1), Inefficacious (4/1), Overextended (6/6), Involved (5/6). In each case as the number of resources goes up relative to the number of demands, the teachers experience lower burnout. In fact, even though the Involved profile group has the same number of demands as the Detached group $(n=5)$, the Involved group has sufficient resources to meet them-- and so they remain resilient. The Over-extended group has a matched number of resources and demands $(n=6)$, which supports the balance they are demonstrating by their placement in the middle of all three burnout scales. Previous research supports this trend: work overload, challenges with work/home balance and emotional challenges of work did not result in burnout when employees had social support and administrator support, including feedback, and job autonomy (Bakker et al., 2005). 
The outlier in this trend is the most effective group - the Engaged group. For this group alone, the number of resources does not follow the pattern, as this most resilient group has six demands but only one resource. It is helpful to explore the nature of the correlated resource to explain this outcome for the Engaged group. Specifically, the Engaged group demonstrated that their level of depersonalization was negatively correlated with their support from introspective activities such as journaling, counselling, and prayer. This group, the smallest of any of the profile groups, are self-sufficient (as indicated by their lack of perceived supports), energetic (as indicated from their relatively lower levels of exhaustion), and maintain high accomplishment. Indeed, these are likely the teachers who were silenced by accusations of toxic positivity (Sokal, Babb, \& Trudel, 2020e). It seems that for the Engaged group alone, introspective activities provided sufficient resources in order to remain resilient and to thrive under pandemic conditions. This ability to respond to stress with growth and energy has been explored in research related to recovery from trauma. Bonanno and his colleagues (2002; Galatzer-Levy et al., 2013a, 2013b, 2014, 2018; Malgaroli et al., 2017) ran a series of studies examining individuals' responses to challenging events such as divorce, the World Trade Centre attacks, or heart attacks. They showed that resilient individuals are those with flexible self-regulation, a positive world view, and a sense of optimism despite challenging circumstances. Indeed, activities such as prayer, journaling, and counselling would likely enhance one's ability to selfregulate and to create a frame for understanding one's situation within the pandemic. For this group, these introspective activities supported the lowest levels of depersonalization from students, alongside lowest levels of exhaustion and highest levels of accomplishment of any of the groups. That is not to say that all groups would benefit from these specific introspective activities in the same way. Rather, these types of supports are clearly meaningful to the members of the Engaged group and support their resilience during the pandemic.

Fourth, the same type of resources may function differently across profile groups. A case in point is exemplified in administrative support. Both the Involved group and the Over-extended group had significant positive correlations between

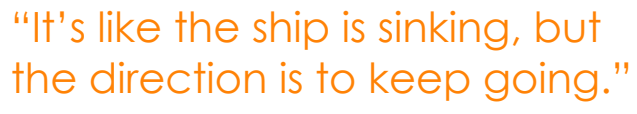
administrative support and accomplishment, whereas the Detached group demonstrated a significant negative correlation between administrative support and exhaustion. In contrast, the Engaged group and the Inefficacious group did not perceive their administrators as significant supports. This may be a function of independence, or a perception that their administrators were not effective-whether assumed or fact. In any case, for the majority of the groups, administrators were identified as important resources.

Fifth, given the increased focus on technology necessitated by the pandemic, the patterns related to technostress and professional learning related to technology seemed contradictory. Specifically, all profile groups except the Inefficacious group perceived technology as a significant demand on their accomplishment-the Over-extended, Engaged, and Involved groups found that their exhaustion was correlated with technology demands, whereas the higher technology demands were correlated with lower accomplishment levels for the Detached group. However, none of the groups perceived that professional learning in new methods of instruction or technology were significant supports. 
Finally, insights can be drawn from the resources that were effective in supporting resilience by teachers across the profile groups. Each group found a specific combination of resources helpful, yet no group used all the resources or the same pattern of resources. This observation speaks to the unique situation of each teacher, their job demands, and the meaningfulness of each resource in their specific contexts. However, given that not all groups were equally successful and within the awareness that not all the resources on the list have been offered to all of the teachers, exploration of ways to maximize both internal and external resources as well as to adjust demands would enhance resiliency across the teacher groups. 


\section{Recommendations}

Just as the pandemic has affected each level and individual in our school system, effective interventions should likewise be multi-level in order to have the greatest results. Some of the original scholars who proposed the job demands-resources model (Bakker \& Demerouti, 2007) have also recently proposed a multi-level response to burnout that is especially helpful in these challenging times (Bakker \& de Vries, 2021). In doing so, they not only operationalized the many years of theorizing about burnout into highly practical uses, but they also addressed the low effects generated by interventions that focus only on individuals or only on organizations. Bakker and de Vries (2021) suggested that interventions are the most effective when they address structural causes of burnout (imbalance between job resources and demands), include multiple response levels (individual and organizational), and do not treat all individuals in the same way. Moreover, the World Health Organization, in its latest edition of the International Classifications of Diseases (ICD 11) has conceptualized burnout as a syndrome and lists its symptoms as the same three variables measured in our research (exhaustion, depersonalization/cynicism, and decreased accomplishment). The ICD 11 defined burnout as a "syndrome resulting from chronic workplace stress that has not been successfully managed" (World Health Organization [WHO], 2018). In so doing, they placed responsibility for mitigation jointly between the individual and the workplace rather than as a function of the individual alone. Within this context, we suggest a range of actions by both individuals and organizations that we suggest will optimize teacher success during the current pandemic conditions (see Figure 9).

When making recommendations of ways to support teachers within the various profile groups, several key guidelines must be observed.

First, we must keep in mind that exhaustion is most closely related to job demands, and that depersonalization and accomplishment are most closely related to resources (Alarcon, 2011). While it is intuitive to want to provide copious resources to people who are highly

"Our school division is just overwhelming us with the number of resources they are finding, and I'm finding that not helpful. They are not focused on finding three or four that work. They are sending us out ten a day, and it's difficult trying to keep up." exhausted, our own research showed that exhausted teachers during the COVID19 pandemic view this as a demand (Sokal, Eblie Trudel \& Babb, 2020c). It is also important to note that while

the detached and over-extended groups in our study indicated the highest exhaustion, the other three groups are also demonstrating elevated exhaustion levels, suggesting that providing copious resources to any of the groups without attention to demand reductions will be less effective. Moreover, there is a consistent relationship in the literature between depersonalisation and resources (Demerouti et al., 2001), with higher depersonalization resulting from lower job resources. 
Indeed, the three groups in the current study who indicated the highest levels of exhaustion also demonstrated the highest levels of depersonalization. This suggests that while resource provision is essential, these resources must be selected carefully for maximum recovery from burnout. Moreover, the subjective value of resources in mitigating exhaustion and depersonalization rests with the teachers, not with those providing the external resources. Resources that are not viewed as useful by teachers will not decrease their stress or burnout.

This raises the second guideline: Teachers who are provided with opportunities for agency and choice are more resilient (Ford et al, 2019). We caution that the recommendations suggested here will be most effective when chosen by a specific teacher at any given point and then modified as the teacher moves toward engagement or away from burnout. A healthy workplace, according to Schaufeli et al. (2009), thrives on engaged employees who are "motivated, proactive, responsible, and involved" (p. 216). An effective approach is adopting a flexible coping repertoire that is responsive to use of

"It is easy to beat up on any government. When this is all said and done, I hope there is a serious look at 'ok this happened. What were our messages?' Teachers are essential workers-- we all understand that, I think. So, I think that if you want people who are essential to not burn out, from a management perspective you have people who can keep doing what they're doing to keep the system running. And you have to provide those people with clear messaging. Even if the messaging is "Hey, this really stinks. Thank you, and here are some resources for you." resources as needed and as the job demands change (Bakker \& de Vries, 2021). Moreover, Schaufeli et al. (2009) suggested that avoiding burnout was essential but insufficient to foster engagement, and that opportunities for growth and development for all employees are the focus in the most efficient workplaces.

\section{Supports for Teachers with Lower Accomplishment}

In terms of the less functional groups who demonstrated high exhaustion, high depersonalization and lower accomplishment (Inefficacious and Detached), attention could be given to opportunities to reset and recover. Individuals who bring work home, ruminate about work issues, and fail to recharge have been shown to experience higher long-term stress and find themselves with depleted personal resources and energy, making them unable to access social supports and other resources (Bakker \& Oerlemans, 2019). While a sustained focus on unproductive avoidance behaviors (e.g., denial and self-blame) will do little to address the demand-resource imbalance, result in poorer work performance, and in turn produce more strain on the employee, a short -term focus on productive recovery strategies can be effective in decreasing job demands and burnout. Avoidant behaviours may in fact be effective for recovery in the short term-- if an employee uses the time to reset and recharge-- in order to have the capacity to reframe the problem and use subsequent approach strategies for coping (Sonnentag, 2012). These supports could include well-being activities, physical health activities, and introspective activities. Moreover, when the stressors cannot be controlled-such as the 
challenges of constant change during a pandemic-- then using strategies to control one's emotional responses to them may be effective (Britt et al., 2016).

\section{Continuum of Resources to Promote Resilience in Teachers}

\author{
Job Crafting - Individual \\ Align skills/talents with preferences/aspirations \\ Seek challenges in existing work \\ Access job/personal resources
}

\author{
Engaged \\ $N=94(6 D, I R)$ \\ Involved \\ $N=175(5 D, 6 R)$ \\ Over-Extended \\ $N=282(6 D, 6 R)$ \\ Inefficacious \\ $N=288(4 D, 1 R)$ \\ Detached \\ $N=180(5 D, 1 R)$
}

\author{
Job Crafting - Organizational \\ Provide coaching and mentoring \\ Encourage participation in planning
}

Facilitate professional learning for well-being

\author{
RESILIENT \\ Shoring up \\ resources to \\ proactively \\ decrease \\ stressors
}

Dysregulated

coping and

avoidance

BURNOUT

Recovery Training - Individual

Recovery Training - Organizational

Detach from work during leisure hours

Ensure regular contact with team members

Lower activation levels during non-work time

Explore something positive and new opportunities

Recognize and regulate job strain

Support, feedback and growth

Figure 9: Continuum of Resources to Promote Resilience in Teachers 
While it would seem more intuitive to ask teachers who are struggling to perform their roles to 'lean in' to confront their stressors (Shin et al., 2014) and to encourage them to use tactics such as seeking social support, focussed adherence to these sorts of 'approach' responses

"The December break definitely recharged me. I feel my energy is restored. I mean I feel some hope things will start changing with the vaccine rolling out. So, I feel hopeful." have their drawbacks over the long term. Demerouti at al. (2007) showed that as resources deplete at work, individuals feel a need for recovery to re-establish their baseline energy and focus. Those who do not adequately recover at home return to work

with less capability to concentrate, which results not only in more fatigue at work, but lower job performance. For those exhausted workers who continue their work tasks at home (Demerouti et al, 2007), the focus and energy they expend to try to fill the gap between job demands and resources may be pulled from usual recovery responses such as exercise and sleep, resulting in a short-term burst of energy but a long-term depletion of vitality (Bakker \& de Vries, 2021). Indeed, the Detached and Inefficacious groups in our sample under-utilized resources such as physical health and well-being activities and introspective activities when compared to the Overextended and Involved groups, who coped more effectively and used all three of these resources.

Importantly, all of the profile groups in our study indicated that home/work balance and time management demands were both significantly correlated with their levels of exhaustion, indicating that ineffective use of their recovery time outside of the workday may have compromised their access to energy.

Recovery involves using time away from work to reset, return energy and emotions to baseline, and may include activities such as hobbies, meditation, social activities, sports, and exercise. Sonnentag and Fritz (2007) showed that the essential attributes of the activity selected must meet four criteria in order to support recovery: (1) it must foster psychological detachment from thinking about work; (2) it must promote relaxation with lower activation levels; (3) it must promote a sense of mastery by learning something new or achieving a goal; (4) it must promote a sense of individual control. In meeting these criteria, recovery activities result in decreased fatigue, increased energy, and increased work performance and engagement.

Other unhealthy results of job strain are self-undermining behaviours (Bakker \& de Vries, 2021), which include poor communication, conflicts with others, and careless mistakes. These behaviours in turn lead to greater job stress and can contribute to tensions for the individual within the imbalance in demands and resources inherent in the situation. Bakker and Wang (2019) showed that these sorts of self-undermining behaviours were more common in employees with higher exhaustion and cynicism (such as the Detached and Inefficacious groups) and occurred most frequently in time periods when the demands were high (Bakker et al., 2020; Bakker \& de Vries, 2021). Indeed, while the Involved and Over-extended groups in our study reported significant correlations with administrator supports and support from friends and family, the Detached group reported only administrative support and the Inefficacious group reported no human supports (administrator, colleagues and parents/guardians, friends and families), suggesting that self-undermining behaviours might be sabotaging opportunities for 
workplace supportive social relationships. When employees enact a maladaptive cycle of response to job demands in a repeated manner, they are more likely to burn out (Bakker \& de Vries, 2021), highlighting the need for interventions that provide more healthy ways of coping.

\section{Importance of Administrators for Teachers with Low/Moderate Accomplishment}

This is where the efforts of an effective administrator can be especially salient. Maricutoiu et al. (2016) conducted a meta-analysis that showed that the majority of interventions focus on increasing employees' personal resources through social support and relaxation. These resulted in small, desirable effects on relieving exhaustion, but no effects on depersonalization/cynicism or accomplishment. As a supplementary process, workplace leaders who adopt a transformative leadership style have been shown to foster reduced job demands through mentoring and coaching (Bakker \& de Vries, 2021), support, feedback, and growth opportunities (Breevaart et al., 2014). For example, Dimoff et al. (2016) showed that supervisors who underwent professional development in mental health literacy developed more positive attitudes toward mental health, higher intentions of promoting mental health practices, resulting in fewer short-term disability claims in their employees. Leaders who gave employees power through "providing additional responsibility, decision-making authority, and resources" (Bakker \& de Vries, 2021) promoted more receptiveness to job interventions by their employers (Thun \& Bakker, 2018).

Interviews conducted with a sub-sample of the teachers from the current study and reported in a previous manuscript (Eblie Trudel, Sokal, \& Babb, in press) demonstrated that teachers experienced decreased exhaustion while concurrently building social support by participating in group planning of inquiry-based units. In this way, the work demands were divided while the accomplishment was maximized. Although interventions such as the aforementioned strategies result in increased resources and decreased burnout, highly stressed employees are less likely to adopt them (Bakker \& de Vries, 2021) and need support in doing so. Indeed, our interview data (Eblie Trudel, Sokal, \& Babb, in press) demonstrated that teachers who were encouraged by their administrators to turn off their computers and leave their job demands

"My school leadership has been extraordinary during this time. They have made efforts to support and encourage teachers." behind at the end of the regular work day reported better coping and less stress in their teaching in the initial stages of the pandemic.

The Canadian Mental Health Association (CMHA) offers workshops to help organizations respond in appropriate ways to workplace stress. One program is called Specialized Management Awareness and Response Training (easy to remember with the acronym SMART). This workshop educates workplace leaders, such as school administrators, in ways to understand and support their employees' mental health. Another is Psychological Health and Safety Advisor training, a certified training program that gives administrators the skills to implement the National Canadian Psychological Health and Safety standard. Please see Appendix B for a full list of resources prepared and recommended by $\mathrm{CMHA}$ in response to our current findings. 


\section{Supports for Teachers with Moderate Accomplishment}

Once teachers are at a point where they have the energy to adopt approach strategies, selecting a strategy that works effectively is important. The most effective strategies are at least ten weeks in duration and involve regular, weekly practices or meetings of 60-90 minutes. Less frequent or shorter durations are less effective (Embse et al., 2019). Moreover, while most studies report small to medium effect sizes for burnout interventions (Embse et al, 2019), some research suggests that there may be a lag effect where effects grow over time after the completion of the intervention (lancu et al., 2018). The Canadian Mental Health Association (Ela Partyka, Program Director) prepared a list of a list of resources recommended for teachers who are struggling with burnout (See Appendix B), as well as those who are interested in proactively protecting and promoting their mental health. CMHA has an additional recommended document called Return to the Workplace, which is a toolkit for both individuals and organizations navigating the stressors of the pandemic.

\section{Supports for Teachers with Higher Accomplishment}

For teachers who are demonstrating higher levels of capacity, opportunities for continued growth are needed to maintain momentum. Recall that our initial definition of resources highlighted the understanding that they can not only mitigate imbalances, but also "stimulate personal growth, learning, and development" (Bakker \& Demerouti, p. 312). Bakker and de Vries (2021) suggested that job crafting may be a meaningful next step. Job crafting refers to employees' activity of adjusting their work environment including tasks, relationships, and job demands and resources (Bakker \& de Vries, 2021). Research about job crafting in teachers showed that it resulted in increased self-efficacy, and optimism (Van Wingerden et al., 2017). Job crafting contributes to the individual/organizational resource and demands loop, in that it fosters hope, resilience, and optimism that serve as personal resources for employees moving forward, resulting in greater well-being (Oprea et al., 2019).

Van Wingerden and her colleagues conducted research using a 12-hour workshop format over several days that entailed having teachers (1) analyze and rank current job demands in terms of their time requirements, frequency, their process (solitary or group), urgency, and

"Been definitely finding working in learning support more fulfilling and a little bit more dynamic, which makes the day go by quickly. And the kids are fantastic. I've been loving working with all of them. I think we're doing a good job." importance; (2) conduct a personal analysis of their strengths, and motives, as well as personal and organizational obstacles; (3) compare the two analyses to match strengths and motives with challenges and obstacles; (4) craft their professional growth plans to maximize individual resources in order to welcome challenges and decrease obstacles; and (5) enact the plan through short- and long-term goals. The

interesting findings of this study were that some of the outcomes demonstrated short-term loss of engagement at four weeks but long-term gains after one year, similar to other burnout interventions (lancu et al., 2018). Moreover, they resulted in more long-term opportunities for 
feedback and professional development, suggesting that when compared with a control group, the teachers who participated were more open to sustained growth-oriented opportunities. In addition, at the one-year point, the participants demonstrated higher efficacy and in-role performance. Unfortunately, employees under high levels of job strain are unlikely to adopt job crafting strategies, resulting in a vicious cycle of burnout (Rudolph et al., 2017), but teachers who have the capacity and are coping well under these current pandemic conditions can enact their agency in undertaking these sorts of activities. Importantly, the intervention did not result in a decrease in the job demands viewed as obstacles, suggesting that the control of demands is a responsibility of employers rather than employees, and highlighting the expectation of the organization in decreasing work-related obstacles.

\section{The Importance of Multi-level Attention to Burnout}

In addition to individual strategies and support from administrators and colleagues as previously explained, other members of organizations have a role to play in effective burnout interventions. Important players include both senior administrators in the superintendent's department and human resources (HR) departments. Bakker and de Vries (2021) suggested that HR/superintendents'/HR departments could: (1) regularly monitor employee stress levels through collaboration with their school-based leaders, and respond to increased levels in a timely manner; (2) decrease burnout through supportive programming to help employees learn ways to detach from work in their off hours (recovery training); and (3) educate employees in job crafting skills.

The COVID-19 pandemic has challenged and tested our global school system in unprecedented ways and magnitudes. In attempts to support our essential frontline workers in our schools, it is important to both build on existing knowledge about teacher burnout mitigation, as well as to test our prior theorizing with data generated in these new circumstances. In so doing, we will garner all our resources to move forward as effectively as possible in response to the current challenges for teachers and educational organizations.

We conclude our recommendations with the advice of Dr. Stan Kutcher (2020).

"It's the long game we're in. And the way it's played will keep changing. Adapt and respond. Use compassion and the best available science. Pivot quickly when necessary. Accept that life is different now. Keep calm and carry on. Reset, not return." 


\section{Appendix A}

\section{Additional Publications and Media About our Research Program}

\section{Peer-Reviewed}

Sokal, L., Eblie Trudel, L., Babb, J. (2020). Supporting teachers in times of change: The job demands-resources model and teacher burnout during the COVID-19 pandemic. International Journal of Contemporary Education, 3 (2). http://redfame.com/journal/index.php/ijce/issue/view/243

Sokal, L., Eblie Trudel, L., \& Babb, J. (2020). Canadian teachers' attitudes toward change and technology, efficacy, and burnout during the initial wave of the COVID-19 pandemic. International Journal of Educational Research- Open. https://doi.org/10.1016/j.ijedro.2020.100016

Eblie Trudel, L., Sokal, L., \& Babb, J. (in press). Teachers' voices: Pandemic lessons for education in times of uncertainty and change. Journal of Teaching and Learning.

Sokal, L., Eblie Trudel, L., \& Babb, J. (2021). I've had it! Factors associated with burnout and low organizational commitment in Canadian teachers during the second wave of the COVID19 Pandemic. International Journal of Educational Research-Open.

10.1016/j.ijedro.2020.100023

https://www.sciencedirect.com/science/article/pii/S2666374020300236

Babb, J., Sokal, L., \& Eblie Trudel, L. (in preparation). This is us: Latent Profile Analysis of Canadian Teachers Burnout during the COVID-19 Pandemic (tentative title).

Sokal, L. \& Babb, J. (under review). Is Demoralization a Profile of Teacher Burnout? Paper submitted to the McGill Journal of Education.

\section{Professional Journals}

Sokal, L., Eblie Trudel, L., \& Babb, J. (2020, June 16). How to prevent teacher burnout during the coronavirus pandemic. The Conversation Canada. (Over 26,000 reads) https://analytics.theconversation.com/ca/institutions/university-of-winnipeg3096/540/articles/dates/20200516/20200616

Sokal, L., Eblie Trudel, L., \& Babb, J. (2020). COVID-19: Supporting teachers in times of change. https://edcan.atavist.com/teacher-covid-survey EdCan (formerly the Canadian Education Association) approached us to offer a free infographics series about our research. 
Sokal, L, Eblie Trudel, L., \& Babb, J. (November 20, 2020). COVID-19's Second Wave: How are teachers faring with the return to physical schools? https://edcan.atavist.com/teachercovid-survey-2

Sokal, L., Eblie Trudel, L., \& Babb, J. (2020, Winter). Opportunity solving: Ordinary people doing extraordinary things, every day. Education Canada.

https://www.edcan.ca/articles/opportunity-solving/ This article was invited as a department article, and then elevated to the lead article for a three-volume series on teacher wellness.

Sokal, L., Eblie Trudel, L., \& Babb, J. (2020, Fall). It's okay to be okay too. Why calling out teachers' "toxic positivity" may backfire. Education Canada, 60(3) https://www.edcan.ca/articles/its-ok-to-be-ok-too/

Sokal, L., Eblie Trudel. L., \& Babb, J. (2021). Five Pathways to Supporting Teacher Resilience during COVID-19. Manitoba School Counsellor. (in press).

\section{Media}

Free Press, April 27, 2020

https://www.winnipegfreepress.com/special/coronavirus/researchers-aim-to-help-teachers-destress-569992852.html?fbclid=lwAR0Avon7d1FdhlNwV47VU9yp4B3ToZ8KyosZeQxHHOH3edzs2EnNZPSILk

CTV print: May 4, 2020

https://winnipeg.ctvnews.ca/the-new-tool-to-understand-how-teachers-cope-with-thepandemic-u-of-W-1.4924249

CBC Print French: May 5, 2020

https://ici.radio-canada.ca/nouvelle/1700309/instituteurs-professeurs-cours-distance-defi-aideetude-universite-winnipeg-manitoba

CTV 6 o'clock News Video May 5, 2020

https://winnipeg.ctvnews.ca/video?binld=1.1206950

Education News Canada, May 5, 2020

https://educationnewscanada.com/article/education/level/university/1/832028/new-researchexamines-how-teachers-cope-with-stress-and-change.html

UW Webpage

https://news-centre.uwinnipeg.ca/all-posts/new-research-examines-how-teachers-cope-withstress-and-change/

Winnipeg Free Press June 24, 2020 
https://www.winnipegfreepress.com/special/coronavirus/digital-learning-leaves-teachersexhausted-survey-571477272.html

Laura Sokal and Lesley Eblie Trudel were interviewed on CBC Radio about our work on teacher stress. The show aired on September 10, 2020. https://www.cbc.ca/listen/live-radio/1-29-

information-radio-mb/clip/15797160-u-w-researchers-share-findings-teacher-stress-pandemic

Laura Sokal and Lesley Eblie Trudel were asked to comment on teacher stress during the return to school on Fall 2020. We were quoted in an article on October 16, 2020 in the Winnipeg Free Press: https://www.winnipegfreepress.com/special/coronavirus/winnipeg-teachers-in-constant-state-of-anxietyamid-covid-pandemic-572775781.html

The Editorial Board of the Winnipeg Free Press wrote an article about our work on October 23, 2020 called Teachers await Provincial Support found

at https://www.winnipegfreepress.com/opinion/editorials/stressed-teachers-await-provincial-support572846582.html\#cxrecs s

Laura Sokal and Lesley Eblie Trudel were asked to comment on teacher attrition during the pandemic. We were quoted in an article on December 31, 2020 in the Winnipeg Free Press: https://www.winnipegfreepress.com/special/coronavirus/pandemic-fuelled-stress-hasnttriggered-mass-exodus-of-teachers-in-city-data-shows-573507062.html 


\section{Appendix B}

Resources from CMHA prepared as a specific response to these research findings

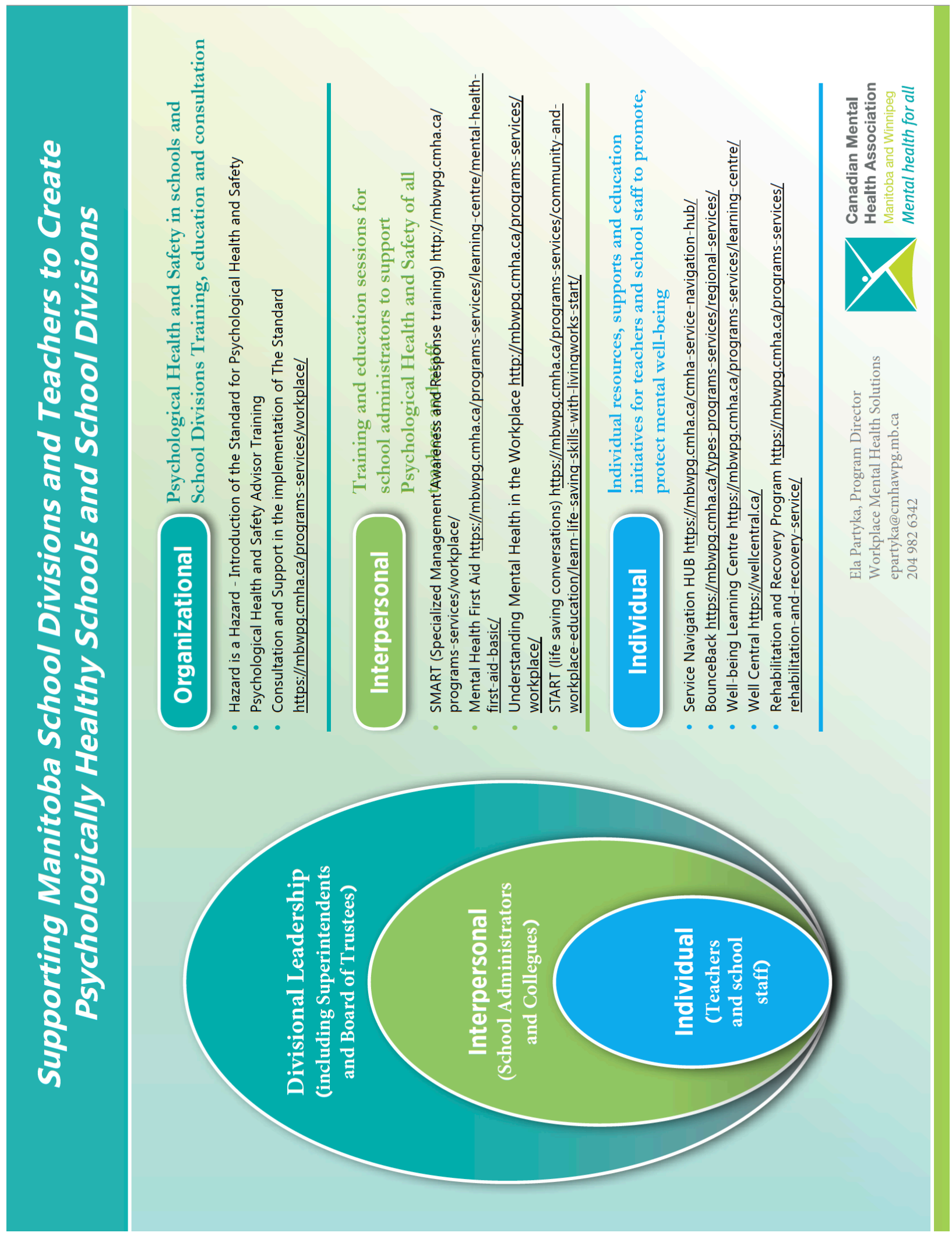




\section{References}

Akogul, S. \& Erisoglu, M. (2017). An approach for determining the number of clusters in a modelbased cluster analysis. Entropy, 19, 452. 10.3390/e19090452

Aguayo, R., Vargas, C., de la Fuente, E., \& Lozano, L. (2011). A meta-analytic reliability generalization study of the Maslach Burnout Inventory. International Journal of Clinical and Health Psychology, 11(2), 343-36.

Alarcon, G. M. (2011). A meta-analysis of burnout with job demands, resources, and attitudes. Journal of Vocational Behavior, 79(2), 549-562. https://doi.org/10.1016/j.jvb.2011.03.007

Al-Fudail, M., \& Mellar, H. (2008). Investigating teacher stress when using technology. Computers \& Education, 51(3), 1103-1110. https://doi.org/10.1016/j.compedu.2007.11.004

Asparouhov, T. \& Muthén, B. (2014). Auxiliary variables in mixture modeling: three-step approaches using Mplus. Structural Equation Modeling: A Multidisciplinary Journal, 21(3), 329-341. https://doi.org/10.1080/10705511.2014.915181.

Babb, J., Sokal, L., \& Eblie Trudel. (under review). THIS IS US: Latent Profile Analysis of Canadian Teachers' Burnout during the COVID-19 Pandemic.

Bakker, A. B., \& Demerouti, E. (2007). The job demands-resources model: State of the art. Journal of Managerial Psychology, 22, 309-328. 10.1108/0142545071082612

Bakker, A. B., \& Demerouti, E. (2014). Job demands-resources theory. In C. Cooper \& P. Chen (Eds.). Wellbeing: A complete reference guide (pp. 37-64). Chichester: Wiley-Blackwell.

Bakker, A. B., Demerouti, E., \& Euwema, M. C. (2005). Job resources buffer the impact of job demands on burnout. Journal of Occupational Health Psychology, 10(2), 170-180. https://doi.org/10.1037/1076-8998.10.2.170

Bakker, A., \& de Vries, D. (2021) Job Demands-Resources theory and self-regulation: new explanations and remedies for job burnout. Anxiety, Stress, \& Coping, 34(1), 1-21. 10.1080/10615806.2020.1797695

Bakker, A. B., \& Oerlemans, W. G. M. (2019). Daily job crafting and momentary work engagement: A self-determination and self-regulation perspective. Journal of Vocational Behavior, 112, 417-430. https://doiorg.uwinnipeg.idm.oclc.org/10.1016/j.jvb.2018.12.005

Bianchi, R., Schonfeld, I. S., \& Laurent, E. (2015). Is burnout separable from depression in cluster analysis? A longitudinal study. Social Psychiatry and Psychiatric Epidemiology, 50(6), 1005-1011. https://doi. org/10.1007/s00127-014-0996-8.

Boldrini, E., Sappa, V., \& Aprea, C. (2019). Which difficulties and resources do vocational teachers perceive? An exploratory study setting the stage for investigating teacher resilience in Switzerland. Teachers and Teaching, 25(1), 125-141. https://doi.org/10.1080/13540602.2018.1520086

Bonanno, G. A., Wortman, C. B., Lehman, D. R., Tweed, R. G., Haring, M., Sonnega, J., ... Nesse, R. M. (2002). Resilience to loss and chronic grief: A prospective study from pre-loss to 18months post-loss. Journal of Personality and Social Psychology, 83(5), 1150-1164. https://doi.org/10.1037/0022-3514.83.5.1150

Bouckenooghe, D. (2009). Change recipients' attitudes toward change: A review study. Vlerick Leuven Gent Working Paper Series, 14, 201-217 https://public.vlerick.com/Publications/6f43ee88-6aa9-e011-8a89-005056a635ed.pdf 
Breevaart, K., Bakker, A. B., Hetland, J., Demerouti, E., Olsen, O. K., \& Espevik, R. (2014). Daily transactional and transformational leadership and daily employee engagement. Journal of Occupational and Organizational Psychology, 87(1), 138- 157. https://doi.org/10.1111/joop.12041

Britt, T. W., Crane, M., Hodson, S. E., \& Adler, A. B. (2016). Effective and ineffective coping strategies in a low-autonomy work environment. Journal of Occupational Health Psychology, 21(2), 154-168. https://doi.org/10.1037/a0039898

Brudnik, M. (2011). Professional burnout in female and male physical education teachers: a fourphase typological model. Human Movement, 12(2), 188-195. https://doi.org/10.2478/v10038-011-0018-6.

Clunies-Ross, P., Little, E., \& Kienhuis, M. (2008). Self-reported and actual use of proactive and reactive classroom management strategies and their relationship with teacher stress and student behaviour. Educational Psychology, 28(6), 693-710. https://doi.org/10.1080/01443410802206700

Cohen, J. (1992). A Power Primer. Psychological Bulletin, 112(1), 155-159.

Collie, R. J., \& Martin, A. J. (2017). Teachers' sense of adaptability: examining links with perceived autonomy support, teachers' psychological functioning, and students' numeracy achievement. Learning and Individual Differences, 55, 29-39.

https://doi.org/10.1016/j.lindif.2017.03.003

Conley S., \& You, S. (2018). Teacher role stress, satisfaction, commitment, and intentions to leave: A structural model. Psychological Reports, 105(3) 771-786.

Crawford, E., LePine, J., \& Rich, B. (2010). Linking job demands to employee engagement and burnout: A theoretic extension and meta-analytic test. Journal of Applied Psychology, 95(5), 834-848. https://doi.org/10.1037/a0019364

Demerouti, E., Bakker, A, Nachreiner, F., \& Schaufeli, W. (2001). The job demands-resources model of burnout. Journal of Applied Psychology, 86(3), 499-512. https://doi.org/10.1037/0021-9010.86.3.499

Demerouti, E., Taris, T., \& Bakker, A. (2007). Need for recovery, home-work interference and performance: Is lack of concentration the link? Journal of Vocational Behavior, 71, 204220.

Dimoff, J. K., Kelloway, E. K., \& Burnstein, M. D. (2016). Mental Health Awareness Training (MHAT): The development and evaluation of an intervention for workplace leaders. International Journal of Stress Management, 23(2), 167-189. https://doi.org/10.1037/a0039479

Dorcet, A., Netolicky, D., Timmers, K., \& Tuscano, F. (2020). Thinking about pedagogy in an Unfolding Pandemic: In Independent report to Written to Inform the work of Education International and UNESCO. http://issuu.com/educationinternational/docs/research/2020_covid-19_eng

Eblie Trudel, L., Sokal, L., \& Babb, J. (in press). Teachers' voices: Pandemic lessons for the future of education. Journal of Teaching and Learning.

Edison, S.W. \& Geissler, G.L. (2003). Measuring attitudes towards general technology: Antecedents, hypotheses and scale development. Journal of Targeting, Measurement and Analysis for Marketing, 12(2), 137-156.

Embse, N., Ryan, S. V., Gibbs, T., \& Mankin, A. (2019). Teacher stress interventions: a systematic review. Psychology in the Schools, 56(8), 1328-1343. https://doi.org/10.1002/pits.22279 
Eyal, O. \& Roth, G. (2011) Principals' leadership and teachers' motivation: Self-determination theory analysis. Journal of Educational Administration, 49(3) 256-275.

Ford, T.G., Olsen, J., Khojasteh, J., Ware, J., \& Urick, A. (2019). The effects of leader support for teacher psychological needs on teacher burnout, commitment, and intent to leave. Journal of Educational Administration, 57(6), 615-634.

Galatzer-Levy, I. R., \& Bonanno, G. A. (2014). Optimism and death: Predicting the course and consequences of depression trajectories in response to heart attack. Psychological Science, 5(12), 2177-2188. https://doi.org/10.1177/0956797614551750

Galatzer-Levy, I. R., Bonanno, G. A., Bush, D. E. A., \& LeDoux, J. E. (2013a). Heterogeneity in threat extinction learning: Substantive and methodological considerations for identifying individual difference in response to stress. Frontiers in Behavioral Neuroscience, 7, Article 55. https://doi.org/10.3389/fnbeh.2013.00055

Galatzer-Levy, I. R., \& Bryant, R. A. (2013b). 636,120 ways to have posttraumatic stress disorder. Perspectives on Psychological Science, 8(6), 651-662.

https://doi.org/10.1177/1745691613504115

Galatzer-Levy, I. R., Huang, S. H., \& Bonanno, G. A. (2018). Trajectories of resilience and dysfunction following potential trauma: A review and statistical evaluation. Clinical Psychology Review, 63, 41-55. https://doi.org/10.1016/j.cpr.2018.05.008

Harmsen, R., Helms-Lorenz, M., Maulana, R., \& van Veen, K. (2018). The relationship between beginning teachers' stress causes, stress responses, teaching behaviour and attrition. Teachers and Teaching, 24(6), 626-643. https://doi.org/10.1080/13540602.2018.1465404

Herman, K., Hickmon-Rosa, J., \& Reinke, W. (2018). Empirically derived profiles of teacher stress, burnout, self-efficacy, and coping and associated teacher outcomes. Journal of Positive Behavioural Interventions, 20(2), 90-100. 10.1177/1098300717732066

Holmes, E., O’Connor, R., Perry, V., Tracey, I, Wessly, S., Arseneault, L., ... Ballard, C. (2020). Multi-disciplinary research priorities for the COVID-19 pandemic: a call for action for mental health sciences. Lancet Psychiatry, 7, 547-560. https://doi.org/10.1016/S22150366(20)30168-1

Hughes, A., Matt, J., \& O’Reilly (2015). Principal support is imperative to the retention of teachers in hard-to-staff schools. Journal of Education and Training Studies, 3(1), 129134.

Hulin, C., Netemeyer, R., \& Cudeck, R. (2001). Can a reliability coefficient be too high? Journal of Consumer Psychology, 10(1), 55-58.

Hultell, D., Melin, B., \& Gustavsson, J. P. (2013). Getting personal with teacher burnout: a longitudinal study on the development of burnout using a person-based approach. Teaching and Teacher Education, 32, 75-86. http://dx. doi.org/10.1016/j.tate.2013.01.007

Iancu, A. E., Rusu, A., Măroiu Cristina, Păcurar Roxana, \& Maricuțoiu, L. P. (2018). The effectiveness of interventions aimed at reducing teacher burnout: a metaanalysis. Educational Psychology Review, 30(2), 373-396. https://doi.org/10.1007/s10648-017-9420-8 
Jennings, P. A., \& Greenberg, M. T. (2009). The prosocial classroom: Teacher social and emotional competence in relation to student and classroom outcomes. Review of Educational Research, 79, 491- 525. https://doi.org/10.3102/0034654308325693

Johnson, S., Cooper, C., Cartwright, S., Donald, I., Taylor, P., \& Millet, C. (2005). The experience of work-related stress across occupations. Journal of Managerial Psychology 20(2), 178-187. https://doi.org/10.1108/02683940510579803

Kin, M. T., \& Kareem, A. O. (2017). Measuring teacher attitudes toward change: An empirical validation. International Journal of Management in Education, 10(1), 1-23. 10.1504/IJMIE.2017.10005987

Klusmann, U., Richter, D., \& Lüdtke, O. (2016). Teachers' emotional exhaustion is negatively related to students' achievement: Evidence from a large-scale assessment study. Journal of Educational Psychology, 108(8), 1193-1203. https://doi.org/10.1037/edu0000125

Kutcher, S. [@stankutcher].(2020-09-08) [It's the long game we are in. And the way it's played will keep changing. Adapt and respond. Use compassion and best available science. Pivot quickly when necessary. Accept that life is different now. Keep calm and carry on. Reset not return.]

Twitter. https://twitter.com/stankutcher/status/1303276064161005568?s=21

Kyriacou, C. (2001). Teacher stress: Directions for future research. Educational Review, 53, 2735. http://dx.doi.org/10.1080/00131910120033628

Leiter, M. P., \& Maslach, C. (2016). Latent burnout profiles: a new approach to understanding the burnout experience. Burnout Research, 3(4), 89-100.

https://doi.org/10.1016/j.burn.2016.09.001

Mäkikangas, A. \& Kinnunen, U. (2016). The person-oriented approach to burnout: A systematic review. Burnout Research, 3, 11-23. http://dx.doi.org/10.1016/j.burn.2015.12.002

Malgaroli, M., Galatzer-Levy, I. R., \& Bonanno, G. A. (2017). Heterogeneity in trajectories of depression in response to divorce is associated with differential risk for mortality. Clinical Psychological Science, 5(5), 843-850.

https://doi.org/10.1177/2167702617705951

Maricuţoiu, L., Sava, F., \& Butta, O. (2016). The effectiveness of controlled interventions on employees' burnout: A meta-analysis. Journal of Occupational and Organizational Psychology, 89(1), 1-27. https://doi.org/10.1111/joop.12099

Maslach, C., \& Jackson, S.E. (1981). The measurement of experienced burnout. Journal of Occupational Behaviour, 2, 99-113.

Maslach, C., Jackson, S.E., \& Schwab, R.L. (1996). Maslach Burnout Inventory - Educators Survey (MBI-ES). In C. Maslach, S.E. Jackson, \& M.P. Leiter, MBI Study (3d ed). Palo Alto, CA: Consulting Psychologists Press.

Maslach, C., Schaufeli, W., \& Leiter, M. (2001). Job burnout. Annual Review of Psychology, 52, 397-422.

Maulana, R., Helms-Lorenz, M., \& van de Grift, W. (2015). Development and evaluation of a questionnaire measuring pre-service teachers teaching behaviour: A Rasch modelling approach. School Effectiveness and School Improvement 26, 169-194. https://doi.org/10.1080/09243453.2014.939198

McCarthy, C. J., Lambert, R. G., Lineback, S., Fitchett, P., \& Baddouh, P. G. (2015). Assessing teacher appraisals and stress in the classroom: Review of the classroom appraisal of 
resources and demands. Educational Psychology Review, 28, 577-603. https://doi.org/10.1007/s10648-015-9322-6

Meyer, J. P., Stanley, L. J., \& Vandenberg, R. J. (2013). A person-centered approach to the study of commitment. Human Resource Management Review, 23, 190-202. https://doi.org/10.1016/j.hrmr.2012.07.007.

Moeller, J., Ivcevic, Z., White, A. E., Menges, J. I., and Brackett, M. A. (2018). Highly engaged but burned out: intra-individual profiles in the US workforce. Career Development International, 23, 86-105. 10.1108/cdi-12-2016-0215

Oprea, B., Barzin, L., Virga, D., Iliescu, D., \& Rusu, A. (2019). Effectiveness of job crafting interventions: A meta-analysis and utility analysis. European Journal of Work and Organizational Psychology, 28(6), 723-741. https://doi.org/10.1080/ 1359432X.2019.1646728

Ott, M., Hiebert, K., Rodger, S., \& Leschiel, A. (2017). A well place to be: The intersection of Canadian school-based mental health policy with student and teacher resiliency. Canadian Journal of Education, 40(2), 1-30. https://journals.sfu.ca/cje/index.php/cjerce/article/view/2243/2422

Otto, R. (1986). Teachers under stress: Health Hazards in a Work Role and Modes of Response. Melbourne: Hill of Content.

Podalsky, A., Kini, T., Bishop, J, \& Darling-Hammond, L. (2016). Solving the teacher shortage: How to attract and retain excellent educators. https://learningpolicyinstitute.org/prodyct/solving-teacher-shortage

Pyhältö, K., Pietarinen, J., Haverinen, K., Tikkanen, L., \& Soini, T. (2020). Teacher burnout profiles and proactive strategies. European Journal of Psychology of Education, https://doi.org/10.1007/s10212-020-00465-6

Revelle, W. (2020). psych: Procedures for Psychological, Psychometric, and Personality Research. Northwestern University, Evanston, Illinois. R package version 2.0.12. https://CRAN.Rproject.org/package=psych.

Richardson, B., Alexander, A., \& Castleberry, T. (2008). Examining teacher turnover in lowperforming, multicultural schools: Relationships among emotional labor, communication symmetry, and intent to leave. Communication Research Reports, 25(1) 10-22.

Rosenberg J.M., Beymer, P.N., Anderson, D.J., Van Lissa, C.J., Schmidt, J.A. (2018). TidyLPA: an R Rosenberg, J. M., Beymer, P. N., Anderson, D. J., Van Lissa, C. J., \& Schmidt, J. A. (2018). tidyLPA:An R Package to Easily Carry Out Latent Profile Analysis (LPA) Using Open-Source or Commercial Software. Journal of Open Source Software, 3(30), 978. https://doi.org/10.21105/joss.00978

Rudolph, C. W., Katz, I. M., Lavigne, K. N., \& Zacher, H. (2017). Job crafting: A meta-analysis of relationships with individual differences, job characteristics, and work outcomes. Journal of Vocational Behavior, 102, 112-138. https://doi.org/10. 1016/j.jvb.2017.05.008

Rudow, B. (1999). Stress and burnout in the teaching profession: European studies, issues, and research perspectives. New York, NY: Cambridge University Press.

Rupert, P. A., Miller, A. O., \& Dorociak, K. E. (2015). Preventing burnout: What does the research tell us? Professional Psychology: Research and Practice, 46(3), 168174. https://doi.org/10.1037/a0039297

Salmela-Aro, K., Hietajärvi, L., \&Lonka, K. (2019). Work burnout and engagement profiles among teachers. Frontiers in Psychology, 10(2254). 10.3389/fpsyg.2019.02254 
Santoro, D. (2018). Demoralized teachers and what local leaders might do. School Administrator, 75(6), 14-15.

Schaufeli, W., \& Taris, T. (2005). The conceptualization and measurement of burnout: common ground and worlds apart. Work \& Stress, 19(3), 256-262.

Schaufeli, W. B., Leiter, M. P., \& Maslach, C. (2009). Burnout: 35 years of research and practice. Career Development International, 14(3), 204-220.

Shin, H., Park, Y. M., Ying, J. Y., Kim, B., Noh, H., \& Lee, S. M. (2014). Relationships between coping strategies and burnout symptoms: A meta-analytic approach. Professional Psychology: Research and Practice, 45(1), 44-56. https://doi.org/10. 1037/a0035220

Skaalvik, E. M., \& Skaalvik, S. (2015). Job satisfaction, stress and coping strategies in the teaching profession - What do teachers say? International Education Studies, 8, 181-192. https://doi.org/10.5539/ies.v8n3p181

Sokal, L. \& Babb, J. (under review). Is Demoralization a Profile of Teacher Burnout? Paper submitted to the McGill Journal of Education.

Sokal, L., Eblie Trudel, L., Babb, J. (2020a). Supporting teachers in times of change: The job demands-resources model and teacher burnout during the COVID-19 pandemic. International Journal of Contemporary Education, 3 (2). http://redfame.com/journal/index.php/ijce/issue/view/243

Sokal, L., Eblie Trudel, L., \& Babb, J. (2020b). Canadian teachers' attitudes toward change and technology, efficacy, and burnout during the initial wave of the COVID-19 pandemic. International Journal of Educational Research-Open.

https://doi.org/10.1016/j.ijedro.2020.100016

Sokal, L., Eblie Trudel, L., \& Babb, J. (2020c). I've had it! Factors associated with burnout and low organizational commitment in Canadian teachers during the second wave of the COVID19 Pandemic. International Journal of Educational Research-Open. https://www.sciencedirect.com/science/article/pii/S2666374020300236

Sokal, L., Eblie Trudel, L., \& Babb, J. (2020d). Opportunity solving: Ordinary people doing extraordinary things, every day. Education Canada. https://www.edcan.ca/articles/opportunity-solving/

Sokal, L., Eblie Trudel, L., \& Babb, J. (2020e). It's okay to be okay too. Why calling out teachers' "toxic positivity" may backfire. Education Canada, 60(3). https://www.edcan.ca/articles/its-ok-to-be-oktoo/

Sokal, L., Eblie Trudel, L., \& Babb, J. (2020f). COVID-19: Supporting teachers in times of change. https://edcan.atavist.com/teacher-covid-survey

Sokal, L., Eblie Trudel, L., \& Babb, J. (2020g, June 16). How to prevent teacher burnout during the coronavirus pandemic. The Conversation Canada.

https://analytics.theconversation.com/ca/institutions/university-of-winnipeg3096/540/articles/dates/20200516/20200616

Sokal, L., Eblie Trudel, L., \& Babb, J. (2020h, November 20) COVID-19's Second Wave: How are teachers faring with the return to physical schools? https://edcan.atavist.com/teacher-covid-survey-2

Sonnentag, S. (2012). Psychological detachment from work during leisure time: The benefits of mentally disengaging from work. Current Directions in Psychological Science, 21(2), 114-118. https://doi.org/10.1177/0963721411434979

Sonnentag, S., \& Fritz, C. (2007). The Recovery Experience Questionnaire: Development and validation of a measure assessing recuperation and unwinding from work. Journal of Occupational Health 
Psychology, 12(3), 204-221. https://doi.org/10.1037/1076-8998.12.3.204

Taris, T., Leisink, P., \& Schaufeli, W. (2017). Applying occupational health theories to educator stress: Contributions of the jobs-demands resources model (pp. 237-260). In T. McIntyre, S. McIntyre, and D. Francis (Eds), Educator stress: An Occupational health perspective. Huston, TX: Springer. https://doi.org/10.1007/978-3-319-53053-6_11

Thun, S., \& Bakker, A. B. (2018). Empowering leadership and job crafting: The role of employee optimism. Stress and Health, 34(4), 573-581. https://doi.org/10.1002/smi.2818

Tschannen-Moran, M., \& Hoy, A. W. (2001). Teacher efficacy: capturing an elusive construct. Teaching and Teacher Education, 17(7), 783-805.

Tschannen-Moran, M., Woolfolk Hoy, A., \& Hoy, W. K. (1998). Teacher efficacy: Its meaning and measure. Review of Educational Research, 68(2), 202-248.

Tsouloupas, C., Carson, R., Matthews, R., Grawitch, M., Barber, L. (2010). Exploring the association between teachers' perceived student misbehaviour and emotional exhaustion: The importance of teacher efficacy beliefs and emotion regulation. Educational Psychology, 30,173-189.

Urick, A. (2016). The influence of typologies of school leaders on teacher retention: a multivariant class analysis. Journal of Educational Administration, 54(4), 434-468.

Van Maele, D. \& Van Houtte, M. (2015). Trust in school: A pathway to inhibit teacher Burnout? Journal of Educational Administration, 54(4), 434-468.

Van Wingerden, J., Bakker, A. B., \& Derks, D. (2017). The longitudinal impact of a job crafting intervention. European Journal of Work and Organizational Psychology, 26(1), 107-119. https://doi.org/10.1080/1359432X.2016.1224233

World Health Organization. (2018). International classification of diseases for mortality and morbidity statistics (11th Revision). Retrieved from https://icd.who.int/browse11/I-m/en 